\title{
Impact of Antioxidants on Cardiolipin Oxidation in Liposomes: Why Mitochondrial Cardiolipin Serves as an Apoptotic Signal?
}

\author{
Alexey V. Lokhmatikov, ${ }^{1,2}$ Natalia Voskoboynikova, ${ }^{1}$ \\ Dmitry A. Cherepanov, ${ }^{3,4}$ Maxim V. Skulachev, ${ }^{5}$ Heinz-Jürgen Steinhoff, ${ }^{1}$ \\ Vladimir P. Skulachev, ${ }^{2,3}$ and Armen Y. Mulkidjanian ${ }^{1,2,3}$ \\ ${ }^{1}$ School of Physics, University of Osnabrueck, 49069 Osnabrueck, Germany \\ ${ }^{2}$ School of Bioengineering and Bioinformatics, Lomonosov Moscow State University, Moscow 119991, Russia \\ ${ }^{3}$ A.N. Belozersky Institute of Physico-Chemical Biology, Lomonosov Moscow State University, Moscow 119991, Russia \\ ${ }^{4}$ A.N. Frumkin Institute of Physical Chemistry and Electrochemistry of the Russian Academy of Sciences, Leninsky Prospect 31, \\ Moscow 119991, Russia \\ ${ }^{5}$ Institute of Mitoengineering, Lomonosov Moscow State University, Moscow 119991, Russia
}

Correspondence should be addressed to Armen Y. Mulkidjanian; amulkid@uni-osnabrueck.de

Received 25 December 2015; Revised 29 February 2016; Accepted 17 March 2016

Academic Editor: Rebeca Acín-Pérez

Copyright (C) 2016 Alexey V. Lokhmatikov et al. This is an open access article distributed under the Creative Commons Attribution License, which permits unrestricted use, distribution, and reproduction in any medium, provided the original work is properly cited.

\begin{abstract}
Molecules of mitochondrial cardiolipin (CL) get selectively oxidized upon oxidative stress, which triggers the intrinsic apoptotic pathway. In a chemical model most closely resembling the mitochondrial membrane-liposomes of pure bovine heart CL-we compared ubiquinol-10, ubiquinol-6, and alpha-tocopherol, the most widespread naturally occurring antioxidants, with manmade, quinol-based amphiphilic antioxidants. Lipid peroxidation was induced by addition of an azo initiator in the absence and presence of diverse antioxidants, respectively. The kinetics of CL oxidation was monitored via formation of conjugated dienes at $234 \mathrm{~nm}$. We found that natural ubiquinols and ubiquinol-based amphiphilic antioxidants were equally efficient in protecting CL liposomes from peroxidation; the chromanol-based antioxidants, including alpha-tocopherol, were 2-3 times less efficient. Amphiphilic antioxidants, but not natural ubiquinols and alpha-tocopherol, were able, additionally, to protect the CL bilayer from oxidation by acting from the water phase. We suggest that the previously reported therapeutic efficiency of mitochondrially targeted amphiphilic antioxidants is owing to their ability to protect those CL molecules that are inaccessible to natural hydrophobic antioxidants, being trapped within respiratory supercomplexes. The high susceptibility of such occluded CL molecules to oxidation may have prompted their recruitment as apoptotic signaling molecules by nature.
\end{abstract}

\section{Introduction}

During last decades, the pathophysiological aspects of redox homeostasis came into focus of cell research; it has been shown that many diseases lead to oxidative imbalance and an increase in the level of reactive oxygen species (ROS) [16]. The ROS comprise the superoxide anion radical $\left(\mathrm{O}_{2}{ }^{--}\right)$, hydroperoxide $\left(\mathrm{H}_{2} \mathrm{O}_{2}\right)$, and the extremely reactive hydroxyl radical $\left({ }^{\circ} \mathrm{OH}\right)$, as well as nitrogen-containing compounds: nitroxide (NO) and peroxynitrite $\left(\mathrm{ONOO}^{-}\right)$[7-9]. Interaction of ROS with organic molecules could yield organic radicals, such as alkoxyl ( $\left.\mathrm{RO}^{\circ}\right)$ and peroxyl (ROO ${ }^{\circ}$ ) radicals, which can be involved in further oxidation processes [10].

The oxidative damage to nucleic acids, proteins, and lipids, as caused by ROS, is usually considered to be a major factor in the general functional decline of tissues upon aging and age-associated degenerative diseases [2]. In case of Meta$z o a$, the means to limit the ROS-induced damage seem to invoke apoptosis - the programmed cell death via activation of executor caspases and digestion of the cell from the inside [11]. Apparently, when the ROS level in a particular cell reaches a certain threshold, apoptosis is activated to eliminate 


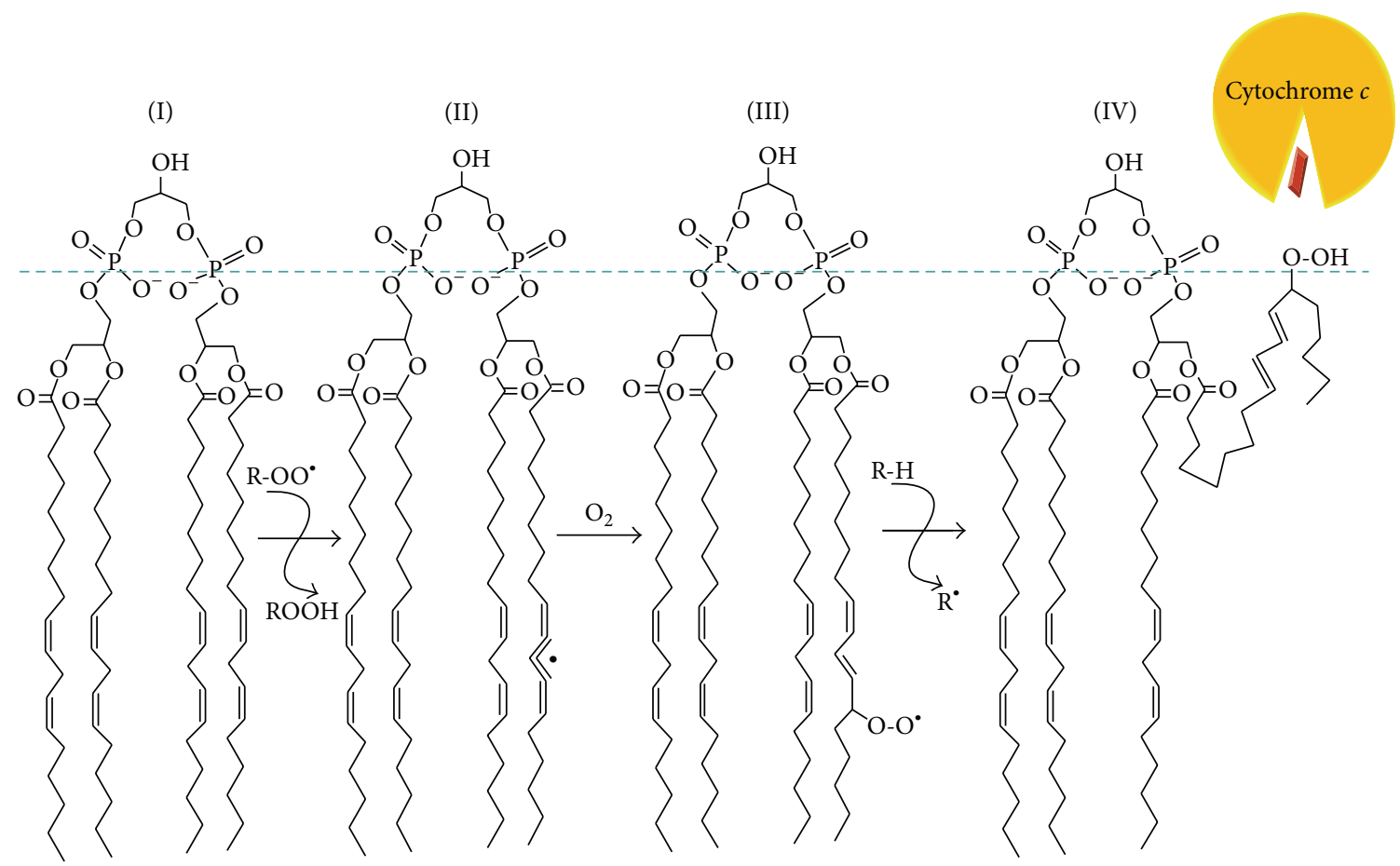

FIGURE 1: Schematic representation of the initial steps of CL peroxidation as based on $[4,10,15-17]$. The mammalian heart CL is mostly found in the form of tetralinoleoyl-CL, that is, with four polyunsaturated residues of linoleic acid (I). A bis-allylic hydrogen atom of CL may be abstracted by a peroxyl radical ( $\mathrm{ROO}^{\circ}$ ) yielding peroxide $(\mathrm{ROOH})$ and a lipid-centered radical (II). The latter is involved in a fast reaction with molecular oxygen and turns into another peroxyl radical, which may consequently attack another polyunsaturated lipid in a chain process. This reaction is accompanied by rearrangement of double bonds of the fatty acid residue, which ultimately leads to the accumulation of conjugated dienes (III). Peroxide of CL exposes its nascent hydrophilic moiety at the surface of the membrane, where it may interact with cytochrome $c$ and turn it into a peroxidase, thus forcing amplification of the oxidation cascade (IV).

the ROS-producing cell, which prevents damaging of the whole tissue; see $[5,12-14]$ for reviews. Apoptosis, generally useful in protecting an organism from oxidative damage, could, however, become counterproductive under conditions of an acute-although potentially reversible-oxidative stress that accompanies such pathological states as stroke and trauma. In such cases, apoptosis could lead to undesirable cell loss, cumulative tissue degradation, and ultimately even to the death of the whole organism. Therefore, a controlled prevention of apoptotic reactions under conditions of acute oxidative stress might save lives.

One of the first signals of the apoptotic pathway within mitochondria is oxidized cardiolipin $[5,13,20,21]$. A cardiolipin (CL) molecule is built of two glycerophosphate moieties, each carrying two fatty acid tails, which are connected via one more glycerol molecule (see Figure 1). Bound CL molecules are seen in the crystal structures of many membrane energy-converting complexes; see $[22,23]$ for reviews. Because of their four fatty acid tails, CL molecules were proposed to promote the interaction between mitochondrial respiratory enzymes [24]. Later, it was shown that CL, indeed, stabilizes supercomplexes formed of the NADH dehydrogenase (mitochondrial complex I), quinol:cytochrome $c$ oxidoreductase (cytochrome $b c_{1}$ complex; complex III), and cytochrome $c$ oxidase (complex IV) [25-28]; a large fraction of loosely bound CL was shown to be affiliated with these supercomplexes [26-28]. Supposedly, CL molecules facilitate the integration of respiratory complexes into dynamic functional units $[29,30]$. In eukaryotes, ROS are produced in mitochondria as byproducts of respiration [31,32]; the major sources of ROS are the NADH : quinone oxidoreductase [33$35]$ and cytochrome $b c_{1}$ complex [9, 36-40], which form CLrich supercomplexes.

The animal variant of CL, which is closely associated with the respiratory complexes and carries polyunsaturated fatty acid chains, can be regarded as an easily "ignitable" compound. The selective peroxidation of CL in mitochondria in response to the oxidative stress was demonstrated with various experimental models [20, 41-45]. Hence, those drugs that protect CL from oxidation might postpone or prevent the cell death.

Recent years have shown notable progress in development and investigation of such drugs; see $[15,46]$ for reviews. It has been shown that some antioxidants can prevent both the oxidation of $\mathrm{CL}$ and the development of pathology. Specifically, idebenone, or 6-(10-hydroxydecyl)ubiquinone, was shown to protect the mitochondrial membrane against lipid peroxidation and improve vascular disorders-owing to strokes or experimental cerebral ischemia-as well as improve the overall brain function [47-50]. Decylubiquinone (decUQ) was shown to block ROS accumulation and prevented activation of the MPT and the cell death in 
the glutathione-depleted cells [51]. Treatment by propofol, a phenolic anaesthetic, was shown to protect against mitochondrial dysfunction [52].

Among others, several mitochondrially targeted antioxidants were developed; see [15, 46] for reviews. Antioxidants based on mitochondrially targeted peptides could concurrently prevent the oxidation of $\mathrm{CL}$, cytochrome $c$ release to the cytoplasm, and the cell death [44, 53-55].

Another way to target drugs to mitochondria is based on a covalent binding of an antioxidant to a penetrating cation. Such cations, termed "Skulachev ions" by Green [56], penetrate through biological membranes in the charged state and get distributed according to the transmembrane difference of electrical potentials [57]. Due to the ability to selectively accumulate in energized mitochondria, which are negatively charged with respect to the cell cytoplasm, such compounds can be used as "locomotives" for delivery of drugs into mitochondria [58]. Since the interior of mitochondria is by approximately $200 \mathrm{mV}$ more negative than the cytosol, penetrating cations can accumulate by a factor of 1000 , at least $[20,58]$. A mitochondrially targeted ubiquinol analogue 10 (6'-ubiquinonyl)decyltriphenylphosphonium (MitoQ), with a triphenylphosphonium group [57] as a penetrating cation, was shown to prevent lipid peroxidation and apoptotic reactions $[59,60]$.

At the Lomonosov University, a series of mitochondrially targeted antioxidants comprised of a penetrating cation and an antioxidant, usually a plastoquinol group, separated by a C-10 linker, have been synthesized and tested. Such compounds were dubbed SkQ ions, that is, conjugates of penetrating Skulachev ions (Sk) and quinols (Q); these constructs were tested in vitro and in vivo [20, 61-74]. SkQs prolonged life of different organisms [68], helped animals to survive after brain and kidney ischemia [69], stroke, and heart attack [64], and decelerated the development of many age-related pathological states, such as cataract and some other eye diseases, balding, achromotrichia, lordokyphosis, and myeloid shift of the blood [20]. Owing to their ability to accumulate in mitochondria $[20,58]$, the $\mathrm{SkQ}$ ions were already efficient when added at concentrations of tens of nanomoles per $\mathrm{kg}$ of body weight.

Upon these studies, it has been shown that CL molecules were specifically peroxidized in mitochondria under oxidative stress, whereas other phospholipids remained more or less intact, and that 10-(6 $6^{\prime}$-plastoquinonyl)decyltriphenylphosphonium (SkQ1) protected the mitochondrial CL from oxidation $[20,63,67]$.

While the physiological protective effects of SkQs and some other mitochondrially targeted antioxidants are well documented (see [46] for a recent review), the mechanism of their action has remained obscure. Indeed, mitochondria possess high levels of powerful natural antioxidants, such as ubiquinols and tocopherols. The concentration of ubiquinol in the mitochondrial membrane is especially high comprising about $1 \%$ of the total lipid content [75], which corresponds to a molar concentration in the order of $10 \mathrm{mM}$. The high level of natural antioxidants in mitochondrial membranes brings us to the conundrum: why the natural stock of ubiquinol and $\alpha$ tocopherol does not fully protect the mitochondrial CL from oxidation, whereas the artificial antioxidants, being externally added in nanomolar amounts [20], could do that?

In an attempt to answer this question, we have established a chemically defined system to quantitatively study the oxidation of CL in the membrane as a function of different antioxidants [19]. We chose pure CL membranes as an object for our kinetic studies and established production of extrusion-derived liposomes of a uniform size of about $100 \mathrm{~nm}$, as confirmed by dynamic light scattering measurements and electron microscopy. The CL liposomes were impermeable for small organic molecules such as 5(6)carboxyfluorescein [19]. To avoid protein-due effects, we initiated the oxidation of CL by an azo initiator $2,2^{\prime}$-azobis(4methoxy-2,4-dimethylvaleronitrile), or MeO-AMVN [18]. The formation of primary oxidation products, conjugated dienes (see Figure 1), was followed, in real time, by measuring their accumulation at $234 \mathrm{~nm}[18,76,77]$. The high efficiency of the hydrophobic initiator MeO-AMVN at low temperatures [18] allowed us to use low amounts of the initiator, which decreased the possible influence of the initiator on the structure of the liposomes. Our method is a direct method, and, along with polarography $[10,78]$, enables continuous tracing of the lipid peroxidation. However, the advantage of the spectrophotometric approach is the ability to simultaneously trace not only the accumulation of the reaction products but also the depletion of the antioxidant, which is essential for kinetic analysis of peroxidation; see Section 2 and [19] for further details on the method used.

With this experimental setup, we have already shown that the amphiphilic quinol-based antioxidants, when added to a solution of CL liposomes, were effective in protecting cardiolipin liposomes from peroxidation even in submicromolar range, with their relative effectiveness depending on the type of antioxidant group and on the nature of the membranetargeted moiety [19].

Here, we have compared natural, hydrophobic antioxidants with artificial, amphiphilic antioxidants in a somewhat amended experimental setup. We have found that natural hydrophobic ubiquinols, when preincubated in liposomes, were as efficient as artificial amphiphilic quinol-containing antioxidants and much more efficient than chromanol-based compounds. The artificial amphiphilic antioxidants, unlike the hydrophobic ubiquinol and $\alpha$-tocopherol, could almost fully inhibit the CL oxidation also when acting from the aqueous phase. We suggest that amphiphilic antioxidants specifically protect those CL molecules which are tightly bound within the enzymes of the respiratory chain, accounting thus for the observed therapeutic effects.

\section{Materials and Methods}

2.1. Chemicals. CL from bovine heart and 1-palmitoyl2-oleoyl-phosphatidylglycerol (POPG) were derived from Avanti Polar Lipids Inc. (Alabaster, AL, US) in the form of lyophilized powder. Yeast ubiquinone- 6 was also from Avanti. Ubiquinone-10 and $\alpha$-tocopherol were bought from Sigma-Aldrich (St. Louis, MO, US). Sodium borohydride and chloroform (99.8\%) were purchased from Roth (Karlsruhe, Germany). Chemicals for buffer solutions were 
<smiles>Cc1c(O)cc(CCCCCCCCC[P+](c2ccccc2)(c2ccccc2)c2ccccc2)c(O)c1C</smiles><smiles>Cc1c(C)c2c(c(C)c1O)CCC(C)(CCCC(C)CCCC(C)CCCC(C)C)O2</smiles><smiles>COc1c(O)c(C)c(CCCCCCCCC[P+](c2ccccc2)(c2ccccc2)c2ccccc2)c(O)c1OC</smiles><smiles>CCCCCCCCCCc1cc(O)c(C)c(C)c1O</smiles><smiles>COc1c(O)c(C)c(C/C=C(\C)CC/C=C(\C)CC/C=C(\C)CC/C=C(\C)CC/C=C(\C)CC/C=C(\C)CC/C=C(\C)CC/C=C(\C)CC/C=C(\C)CC/C=C(\C)CC/C=C(\C)CC/C=C(\C)CC/C=C(\C)CC/C=C(\C)CC/C=C(\C)CC/C=C(\C)CCC=C(C)C)c(C)c1O</smiles>

FIGURE 2: Chemical structures of the tested antioxidants. Quinone-based antioxidants are depicted in their reduced forms (i.e., as quinols).

ordered from Sigma-Aldrich or Roth. Mini-Extruder and the porous membranes were supplied by Avanti. Azo initiator 2,2' -azobis(4-methoxy-2,4-dimethylvaleronitrile), or $\mathrm{MeO}$ AMVN, was delivered by Wako Pure Chemical Industries (Osaka, Japan). HPMC was a gift of Dr. Vitaly Roginsky. Diverse triphenylphosphonium-containing quinone-based antioxidants (see Figure 2) were synthesized in their oxidized (quinone) forms as previously described [63].

2.2. Preparation of Liposomes. The liposomes were produced by extrusion, based on the method of Cullis and coworkers $[79,80]$, similarly to our previous study [19]. Liposomes were prepared by suspending lipid powder in $50 \mathrm{mM}$ sodium phosphate buffer ( $\mathrm{pH}$ 7.4) containing $100 \mu \mathrm{M}$ diethylenetriaminepentaacetic acid (buffer A) to bind possible traces of transition metals, followed by 5 minutes of vortexing to obtain a $3 \mathrm{mg} / \mathrm{mL}$ homogeneous lipid suspension. Whenever an antioxidant was incorporated into liposomes, the lipid powder was mixed with the respective antioxidant in chloroform in a glass beaker and the mixture was dried under a stream of nitrogen for at least 2 hours. Then the lipid film was hydrated by buffer A with a short series of ultrasonication followed by 3 freeze-thawing cycles to obtain lipid suspension consisting of large multilamellar vesicles $(3 \mathrm{mg} / \mathrm{mL})$. In either case large unilamellar vesicles were formed from lipid suspensions by passing them through a $100 \mathrm{~nm}$ pore filter using Mini-Extruder for 19 times. Kinetic studies with liposomes were performed within the day of preparation.

2.3. Converting Quinones to Quinols. Reduction of quinones to corresponding quinols was performed by adding a small amount $(2-3 \mathrm{mg})$ of dry sodium borohydride to $1-2 \mathrm{mM}$ quinone solution in ethanol. The reaction was complete within a minute of intensive mixing. The excess of reductant was removed by a small volume of fuming $\mathrm{HCl}$ followed by at least two centrifugations at $15800 \mathrm{~g}$ (5 minutes each) to remove the sodium borate pellet. Reduced quinones were stored at $-80^{\circ} \mathrm{C}$ until use. The final quinol concentration was determined from the absorbance maximum at $290 \mathrm{~nm}$. The molar absorptivity coefficients used for ubiquinol-6, ubiquinol-10, plastoquinol-based antioxidants $\left(\mathrm{SkQ1H}_{2}\right.$ and decPQH ${ }_{2}$ ), and amphiphilic ubiquinol-based antioxidants $\left(\mathrm{MitoQH}_{2}\right.$ and $\left.\operatorname{dec} \mathrm{UQH}_{2}\right)$ were $4890,3940 \mathrm{M}^{-1} \mathrm{~cm}^{-1}$ [81], $3540 \mathrm{M}^{-1} \mathrm{~cm}^{-1}$ [82], and $4140 \mathrm{M}^{-1} \mathrm{~cm}^{-1}$ [83], respectively. Under acidic conditions the reduced state of quinols was preserved for months. The list of all antioxidants in their reduced forms is presented in Figure 2.

2.4. Oxidation of HPMC. The oxidized form of HPMC (the respective quinone or other products) was achieved by 


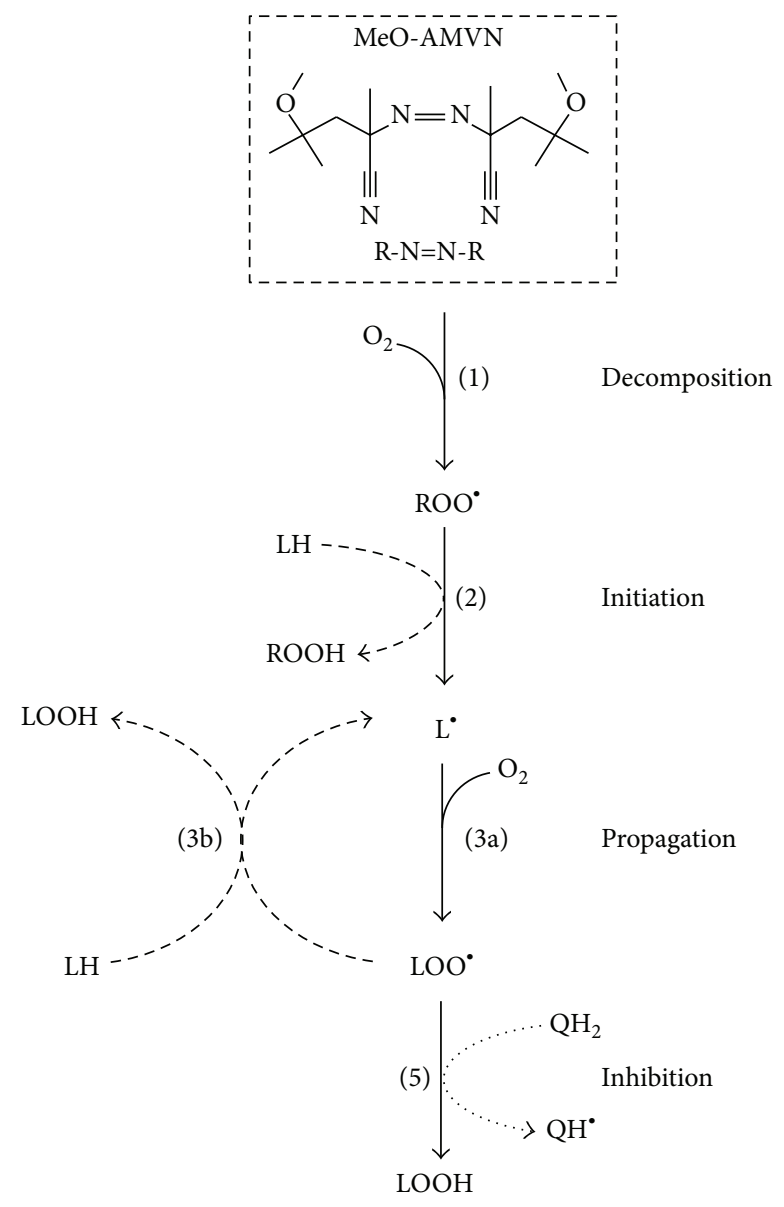

FIGURE 3: Scheme of a chain radical reaction in a system containing an azo initiator $\mathrm{MeO}-\mathrm{AMVN}, \mathrm{CL}$ molecules, and a chain-breaking inhibitor of quinol nature (based on $[4,10,15-18]$ ). The main stages of the process are indicated by numbers corresponding to the respective reactions, as described in Section 2. The radical products of the initiator decomposition (1) $\mathrm{ROO}^{\bullet}$ initiate the oxidative cycle via formation of an alkyl $\left(\mathrm{L}^{\circ}\right)$ radical (2). The reaction propagates $((3 a)$ and $(3 b))$ as this alkyl radical consumes molecular oxygen to form peroxyl $\left(\mathrm{LOO}^{*}\right.$ ) radical (3a), which abstracts a hydrogen atom from another lipid molecule $(\mathrm{LH})$ to yield another $\mathrm{L}^{\circ}$ radical $(3 \mathrm{~b})$. An inhibitor, such as quinol $\left(\mathrm{QH}_{2}\right)$, may break the reaction chain by quenching a $\mathrm{LOO}^{\circ}$ radical (5).

overnight incubation of $5 \mu \mathrm{M}$ HPMC with $10 \mu \mathrm{M}$ of $\mathrm{CuCl}_{2}$ at $40^{\circ} \mathrm{C}$ in $50 \mathrm{mM}$ sodium phosphate $\mathrm{pH}$-buffer, $\mathrm{pH}$ 7.4.

2.5. Experimental Setup for Lipid Peroxidation Assays. As shown in Figure 3, the lipid peroxidation was initiated by an azo initiator, based on approaches described in $[18,76,77]$, similarly as in our previous study [19].

Following Noguchi et al. [18], we launched the peroxidation of CL by adding the peroxyl radical azo initiator $\mathrm{MeO}$ AMVN. This substance spontaneously decomposes, with a rate that is constant at a given temperature, into two carboncentered radicals, which promptly become peroxyl radicals in an oxygen-rich medium (Figure 3 ).
Decomposition:

$$
\begin{gathered}
\mathrm{R}-\mathrm{N}=\mathrm{N}-\mathrm{R} \longrightarrow 2 \mathrm{R}^{\bullet}+\mathrm{N}_{2} \\
\mathrm{R}^{\bullet}+\mathrm{O}_{2} \longrightarrow \mathrm{ROO}^{\bullet}
\end{gathered}
$$

The peroxyl radical $\left(\mathrm{ROO}^{\circ}\right)$ may abstract a bis-allylic hydrogen atom from a polyunsaturated lipid molecule, thus initiating the chain.

Initiation:

$$
\mathrm{ROO}^{\bullet}+\mathrm{LH} \longrightarrow \mathrm{L}^{\bullet}+\mathrm{ROOH}
$$

The resulting carbon-centered lipid radical $\mathrm{L}^{\bullet}$ will further react with oxygen molecules to give a peroxyl radical of a lipid $\left(\mathrm{LOO}^{\circ}\right)$. This radical, in turn, may attack other polyunsaturated lipids, thereby accounting for the propagation of the oxidation chain.

Propagation:

$$
\begin{gathered}
\mathrm{L}^{\bullet}+\mathrm{O}_{2} \rightarrow \mathrm{LOO}^{\bullet} \\
\mathrm{LOO}^{\bullet}+\mathrm{LH} \rightarrow \mathrm{L}^{\bullet}+\mathrm{LOOH}
\end{gathered}
$$

The process continues until two radicals terminate in a bimolecular reaction.

Termination:

$$
2 \mathrm{LOO}^{\bullet} \longrightarrow \text { nonradical products }
$$

These first stages of polyunsaturated fatty acid peroxidation lead to formation of monohydroperoxide accompanied by the rearrangement of double bonds to form conjugated dienes [4, 84, 85] (see Figures 1 and 3). Conjugated dienes have a broad absorption band with a maximum at $234 \mathrm{~nm}$, which can be monitored spectroscopically. If the majority of polyunsaturated fatty acid residues represent linoleic acid, as in the case of bovine heart CL, the number of peroxides formed would be stoichiometrically equal to the number of conjugated dienes formed $[10,86]$. Since we used a mild initiator only capable of producing peroxyl radicals, and the medium was purged from transition metal ions with a chelator, the reaction would halt at the first diene-peroxide stage. This method is both direct, as it quantifies the primary reaction product [10], and precise in terms of the signal to noise ratio.

Chain-breaking antioxidants, such as tocopherols or quinols, react with peroxyl radicals much faster than the bisallylic hydrogen atom of a fatty acid, and thereby can prevent the chain propagation.

\section{Inhibition:}

$$
\mathrm{QH}_{2}+\mathrm{LOO}^{\bullet} \longrightarrow \mathrm{QH}^{\bullet}+\mathrm{LOOH}
$$

The product of such reaction, a semiquinone $\left(\mathrm{QH}^{\circ}\right)$ or an $\alpha$-tocopheroxyl ( $\alpha$-toc ${ }^{\circ}$ ) radical, can either quench another lipid radical species

$$
\mathrm{QH}^{\bullet}+\mathrm{LOO}^{\bullet} \longrightarrow \mathrm{Q}+\mathrm{LOOH}
$$


or be quenched by another radical species of the same antioxidant. In case of semiquinone, this will partly regenerate the initial quinol molecule via disproportionation:

$$
2 \mathrm{QH}^{\bullet} \longrightarrow \mathrm{Q}+\mathrm{QH}_{2}
$$

The products of collision of two $\alpha$-tocopheroxyl radicals may give rise to different substances; see [10].

In the ideal case, when an antioxidant and its oxidationderived radical form both participate in the quenching of lipid peroxyl radicals, the stoichiometry of the inhibition would correspond to two quenched radicals per one consumed antioxidant molecule. In reality, the stoichiometry is usually lower because of losses. For instance, a semiquinone radical can be oxidized by molecular oxygen yielding a superoxide anion and a fully oxidized quinone molecule as products:

$$
\mathrm{QH}^{\bullet}+\mathrm{O}_{2} \longrightarrow \mathrm{Q}+\mathrm{O}_{2}^{\cdot-}+\mathrm{H}^{+}
$$

Ultimately, if the extent of the autooxidation is very high, the stoichiometry of the quenching of peroxyl radicals by quinols may be even close to zero [78, 87]. Unlike quinols, both $\alpha$-tocopherol and its $\alpha$-tocopheroxyl radical are practically nonreactive towards oxygen [88], which implies that $\alpha$-tocopherol and its analogues have an inhibitory stoichiometry of two, being often viewed as reference antioxidants.

Oxidation assays were performed in buffer $\mathrm{A}$ at final $\mathrm{CL}$ concentration of $100 \mu \mathrm{M}$. The sample was incubated in a $3 \mathrm{~mL}$ quartz cuvette inside a UV-2450 spectrophotometer (Shimadzu, Tokyo, Japan) equipped with a Peltier element at $40^{\circ} \mathrm{C}$. The experiment was initiated by addition of $50 \mu \mathrm{M}$ MeO-AMVN.

Oxidation of CL was monitored by changes in absorbance at $234 \mathrm{~nm}$ which corresponds to formation of conjugated dienes $[18,89,90]$. The value taken for the molar absorptivity of conjugated dienes was $27400 \mathrm{M}^{-1} \mathrm{~cm}^{-1}$. Antioxidants themselves also absorbed in the UV range; however their difference "oxidized minus reduced" spectra had isosbestic points close to $234 \mathrm{~nm}$ (Figure 4) and therefore could not notably contribute to the absorbance changes as monitored at $234 \mathrm{~nm}$. Spectra at the wavelengths of $210-300 \mathrm{~nm}$ were recorded every 5 minutes against a reference cuvette containing all the same components, except for MeO-AMVN. The noise produced by the setup was always in the range of 0.002 absorbance units at 230-300 nm. Antioxidants were introduced to both cuvettes either initially, when incorporated into CL liposomes, or 30 minutes after the start of the experiment, when incorporated into POPG liposomes, or added as ethanol solutions. The POPG stock suspension used for antioxidant delivery usually contained 20 or $100 \mu \mathrm{M}$ of antioxidant incorporated into $4 \mathrm{mM}$ of POPG.

2.6. Statistical Analysis of the Data. The statistical analysis was performed with MATLAB software. The data for pure CL oxidation were obtained from five experiments when no antioxidants were incorporated. The data for natural and amphiphilic antioxidants were derived from the plateau region by averaging three runs for each antioxidant incorporated into CL or POPG liposomes, and two runs for
MitoQH $\mathrm{H}_{2}$. The data for HPMC were averaged from five separate runs including experiments with CL incorporation, POPG incorporation, and external addition to CL liposomes in ethanol, as described in our previous publication [19]. The duration of inhibition phase for each antioxidant was determined as a time point of intersection of the lines corresponding to the average kinetics of inhibited and noninhibited oxidation.

\section{Results}

3.1. Preincorporation of Antioxidants into Cardiolipin Liposomes. In the first set of experiments, we incorporated the antioxidants into the hydrophobic lipid phase as described in Materials and Methods. Figures 5(a) and 5(b) show the UV absorbance changes during the MeO-AMVN-induced CL peroxidation in the sample that contained $1 \mu \mathrm{M} \mathrm{Q}_{10} \mathrm{H}_{2}$ incorporated into $100 \mu \mathrm{M}$ of liposomal CL. The most remarkable changes occurred around $234 \mathrm{~nm}$ and $281 \mathrm{~nm}$ (Figure 5(c)), which correspond to the absorption maxima of conjugated dienes and "oxidized minus reduced" ubiquinone (Figure 4), respectively. First, in response to the addition of $\mathrm{MeO}$ AMVN, the fast formation of ubiquinone was observed (Figure 5(c)). Concurrently, a small dip was observed at $290 \mathrm{~nm}$ (Figure 5(b)), which reflected the disappearance of ubiquinol. Only after ubiquinol got exhausted in approximately 100 minutes, a broad peak of conjugated dienes with a maximum at $234 \mathrm{~nm}$ appeared and started to grow (Figure 5(c)). The start of absorbance rise at $234 \mathrm{~nm}$ correlated well with a plateau in the $A_{281}$ kinetics (at a time point of $\sim 100$ minutes). Thus, the protective action of $\mathrm{Q}_{10} \mathrm{H}_{2}$ was not compromised until the full expenditure of the antioxidant.

Figures 6(a) and 6(b) show the kinetics of CL oxidation in the presence of three natural antioxidants, namely, $\mathrm{Q}_{10} \mathrm{H}_{2}$, $\mathrm{Q}_{6} \mathrm{H}_{2}$, and $\alpha$-tocopherol, as well as artificial antioxidants, amphiphilic plastoquinol-based $\mathrm{SkQ1H}_{2}$, and 6-hydroxy2,2,5,7,8-pentamethylbenzochroman (HPMC), a synthetic $\alpha$ tocopherol analogue lacking the hydrophobic tail (see Figure 2 for the structures). The initial slopes of the kinetic curves (see the insert in Figure 6(b)) correspond to the effectiveness of the tested substances as antioxidants. Apparently, the quinol-based antioxidants almost fully protected CL from oxidation, unlike $\alpha$-tocopherol, in the presence of which a notable oxidation of CL still took place. All the quinols, both natural and synthetic, demonstrated equal antioxidant activity, but the duration of the inhibitory action was almost twice longer for $\mathrm{Q}_{10} \mathrm{H}_{2}$ and $\mathrm{Q}_{6} \mathrm{H}_{2}$ as compared with $\mathrm{SkQ} 1 \mathrm{H}_{2}$. The duration of the antioxidant activity of $\alpha$-tocopherol was the longest. The antioxidant potency of HPMC was lower than that of the quinols and slightly higher than that of $\alpha$ tocopherol, although the duration of the induction period was much shorter.

We have also examined other amphiphilic analogues of ubiquinol (see Figure 2 for the structures) using the same experimental setup. Namely, we tested the aforementioned $\mathrm{MitoQH}_{2}$, a compound similar to $\mathrm{SkQ}_{2} \mathrm{H}_{2}$ but with an ubiquinol group instead of the plastoquinol moiety of $\mathrm{SkQ1H}_{2}$ (Figure $7(\mathrm{a})$ ), and amphiphilic short-tail quinols 


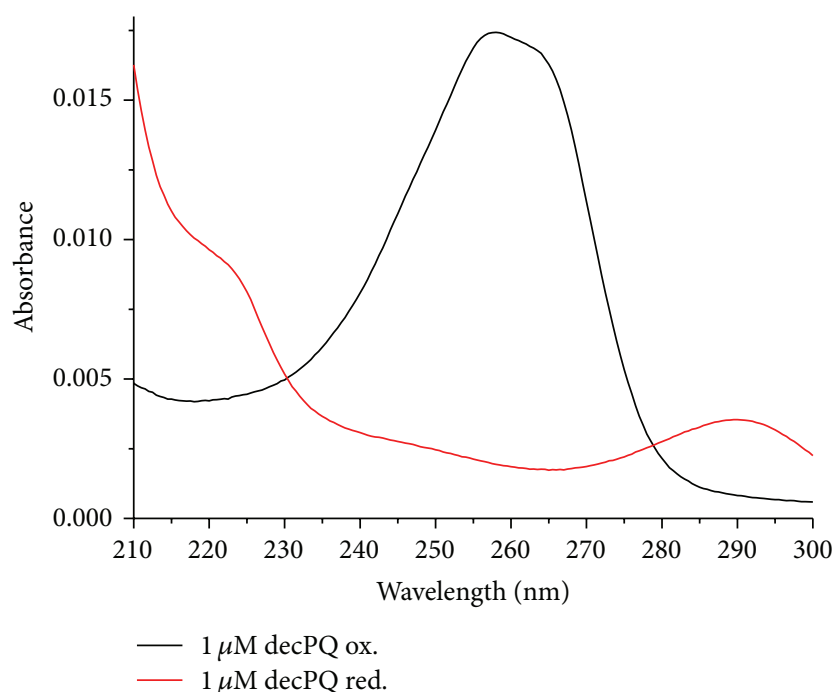

(a)

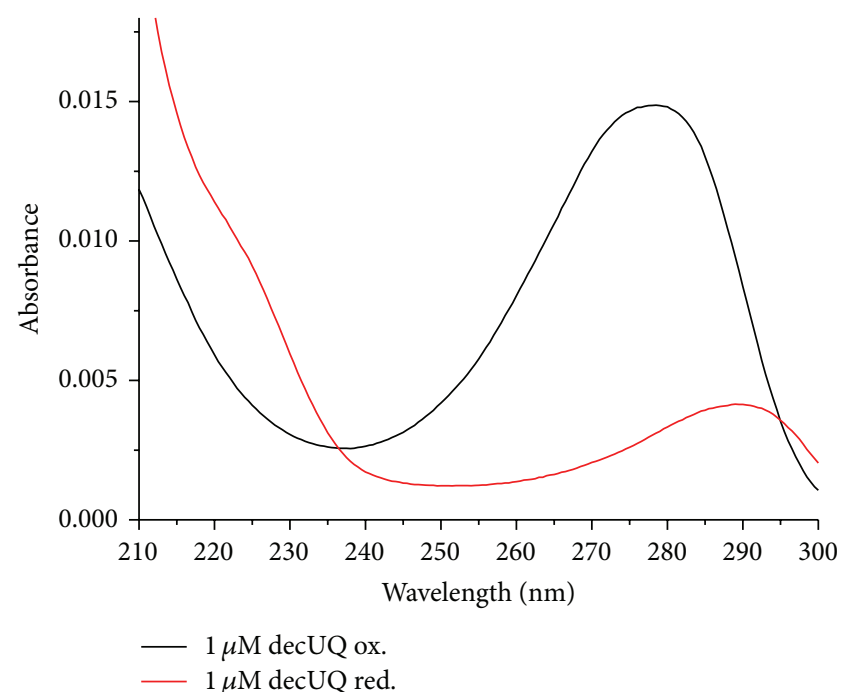

(b)

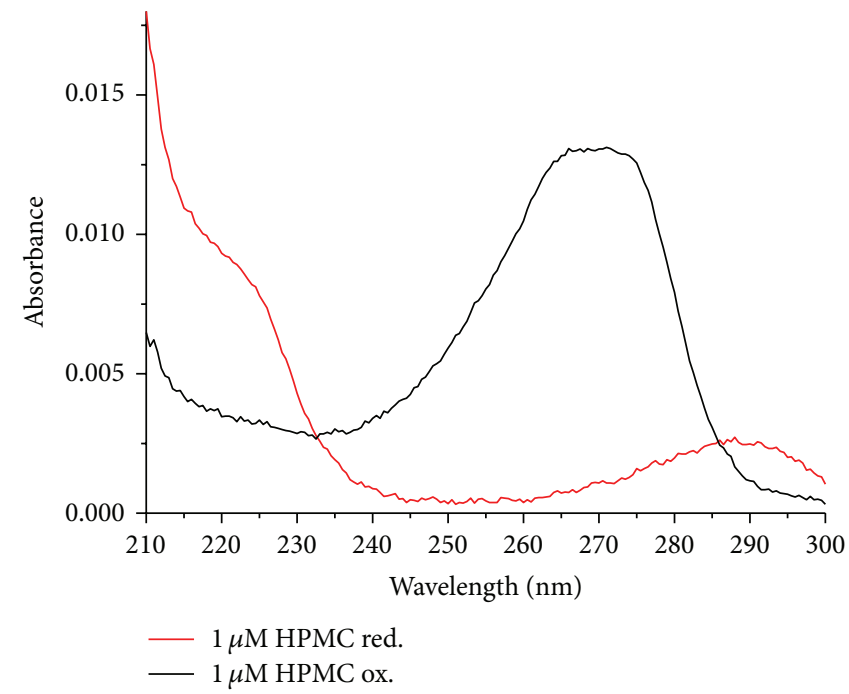

(c)

Figure 4: Spectra of oxidized (black line) and reduced (red line) forms of (a) decPQ, (b) decUQ, and (c) HPMC (see text). The spectra were normalized to $1 \mu \mathrm{M}$ of the substance to assess the impact of oxidation of these compounds into total absorbance changes during the experiment. All the three redox pairs have isosbestic points at $230-240 \mathrm{~nm}$ suggesting a minimal interference with the robust signal of conjugated dienes. The ubiquinone/ubiquinol pair also has an "oxidized minus reduced" difference absorption maximum at $\sim 275 \mathrm{~nm}$, which does not strongly overlap with the spectrum of conjugated dienes.

lacking penetrating cation moieties, $\operatorname{dec} \mathrm{PQH}_{2}$ and $\operatorname{dec} \mathrm{UQH}_{2}$ (Figure 7(b)). In both cases, the antioxidant efficiency of all tested compounds was high, but the duration of protection was almost twice as long in the case of ubiquinol-based antioxidants.

The quantitative comparison of different antioxidants incorporated into CL or POPG liposomes (see also Section 3.2) is given in Figure 8 and Table 1. The data correlate with our previous study where the amphiphilic quinol-based antioxidants were potent inhibitors of CL peroxidation when added externally as ethanol solutions [19].
3.2. Preincorporation of Antioxidants into Nonoxidizable Liposomes. The data in Figures 6-8 and Table 1 indicate that all tested quinol-based antioxidants efficiently protected liposomal CL from oxidation; still with this approach we could not compare the kinetics of CL oxidation in the absence and in the presence of an antioxidant, respectively, because antioxidants were added already upon the preparation of liposomes. In our previous study [19], we added antioxidants as an ethanol solution after liposomes underwent $\mathrm{MeO}-$ AMVN-initiated peroxidation for 30 minutes. This approach, however, is of little use with hydrophobic, water-insoluble 


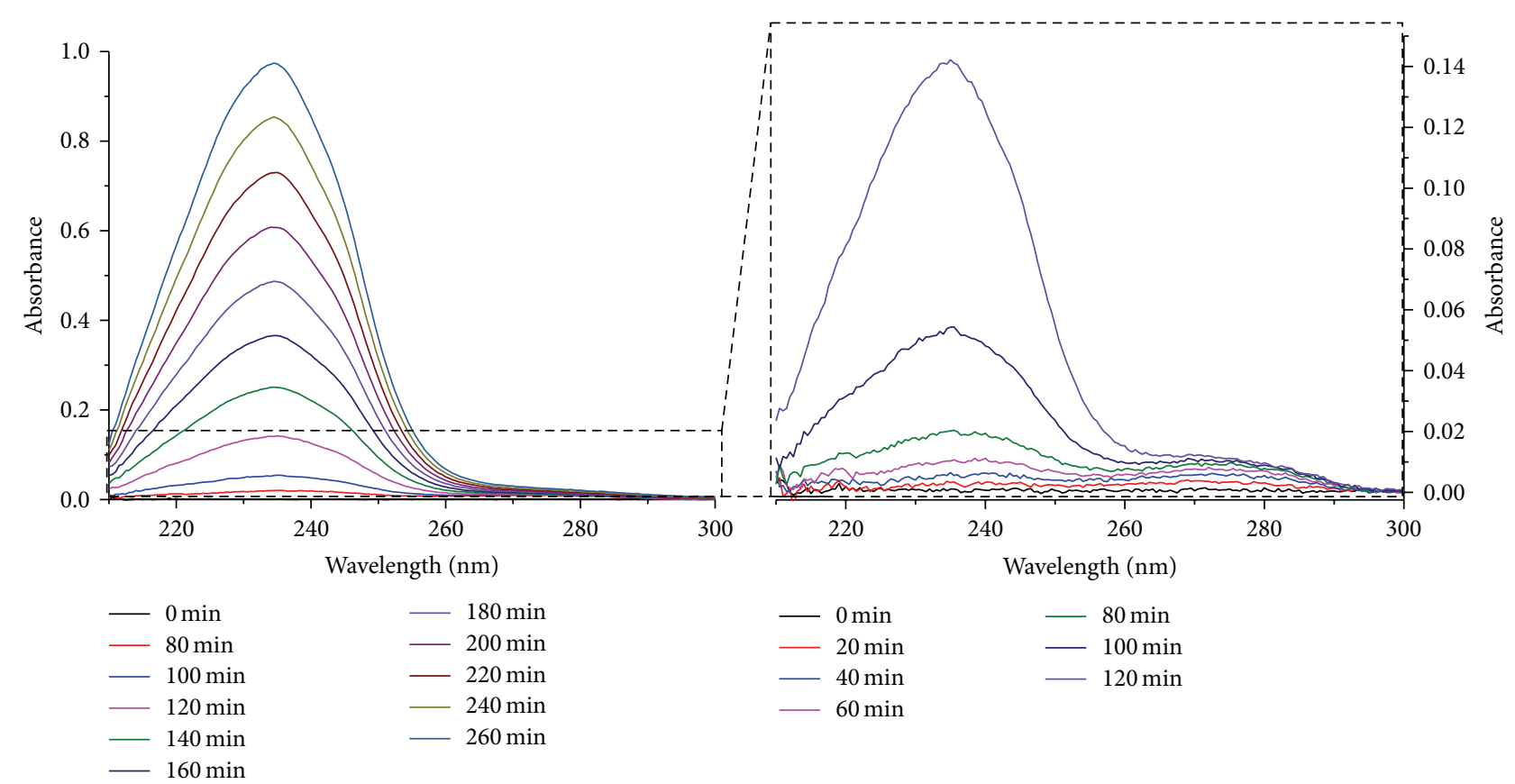

(a)

(b)

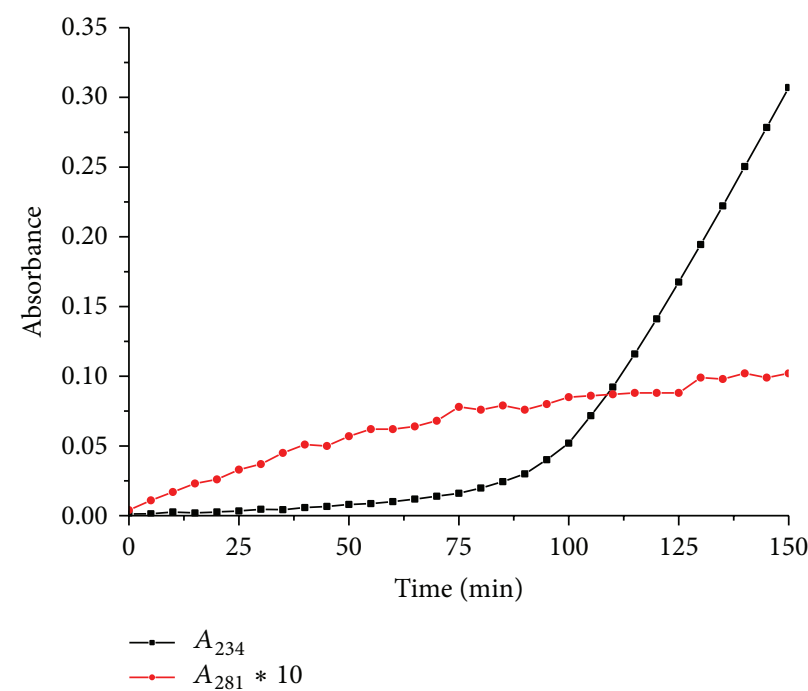

(c)

Figure 5: Prevention of the MeO-AMVN-induced oxidation in CL liposomes by $1 \mu \mathrm{M} \mathrm{Q} \mathrm{Q}_{10} \mathrm{H}_{2}$. Conditions: pH-buffer A (see Section 2), $100 \mu \mathrm{M} \mathrm{CL}, 50 \mu \mathrm{M} \mathrm{MeO}-\mathrm{AMVN}$, and $40^{\circ} \mathrm{C}$. (a, b) Spectral changes of the liposome suspension over the whole time range (a) and during the induction phase (b). (c) Kinetics of absorbance changes at $234 \mathrm{~nm}$ (accumulation of conjugated dienes) and at $281 \mathrm{~nm}$ ("oxidized minus reduced" absorption difference for $\mathrm{Q}_{10}$, cf with Figure $4(\mathrm{~b})$ ) show that lipid peroxidation did not start before the antioxidant $\mathrm{Q}_{10} \mathrm{H}_{2}$ was exhausted.

antioxidants. Therefore, we combined preincorporation of hydrophobic antioxidants into lipid bilayer with an external way of their supplementation to CL liposomes. For this purpose, antioxidants were incorporated into liposomes made of an inert, nonoxidizable lipid 1-palmitoyl-2-oleoylphosphatidylglycerol (POPG), and these antioxidant-loaded liposomes were added to a suspension of CL liposomes that underwent $\mathrm{MeO}-\mathrm{AMVN}$-driven peroxidation for 30 minutes (Figures 9(a) and 9(b)). In this setup we tested the antioxidant potency of $\mathrm{Q}_{10} \mathrm{H}_{2}, \mathrm{Q}_{6} \mathrm{H}_{2}$, and $\alpha$-tocopherol, as well as of $\mathrm{SkQ1H}_{2}$ (Figure 9(a)). The generation of conjugated dienes was essentially blocked by the addition of liposomes that contained $\mathrm{SkQ}_{2} \mathrm{H}_{2}$; the duration of the lag period was similar to that observed earlier when the same antioxidant was added in an ethanol solution ( $60 \mathrm{~min}$, see [19]). Natural hydrophobic antioxidants, being added, within liposomes, to the same final concentration of $1 \mu \mathrm{M}$, retarded the oxidation of CL only slightly, and to the same extent. To understand 


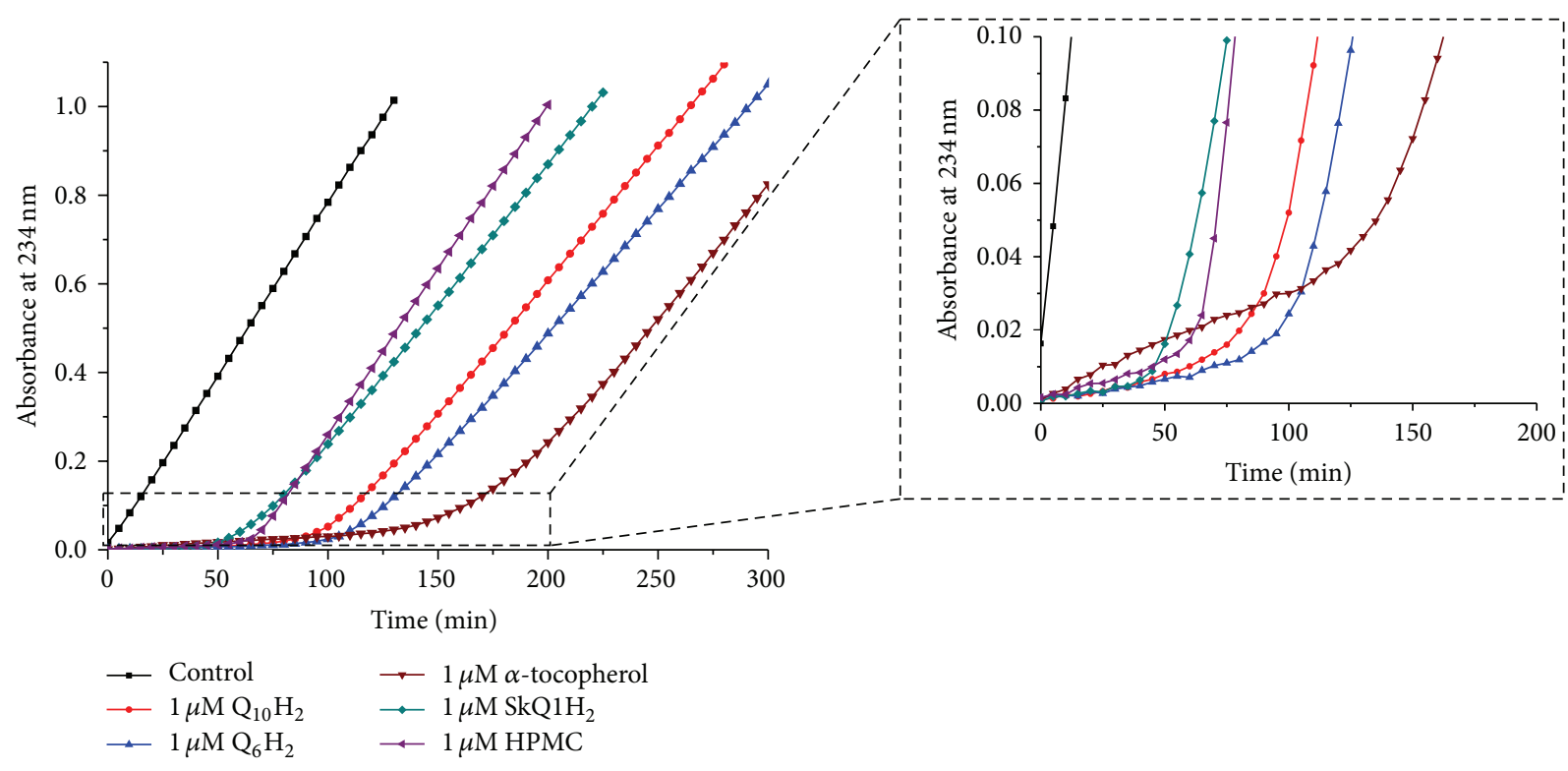

(a)

(b)

Figure 6: Prevention of the MeO-AMVN-induced oxidation of CL liposomes by incorporated natural antioxidants, $\mathrm{SkQ1H}_{2}$ and $\mathrm{HPMC}_{\text {. }}$ Conditions: pH-buffer A (see Section 2), $100 \mu \mathrm{M} \mathrm{CL}, 50 \mu \mathrm{M} \mathrm{MeO-AMVN}$, and $40^{\circ} \mathrm{C}$. (a, b) Kinetics of absorbance changes at $234 \mathrm{~nm}$ in the presence of $1 \mu \mathrm{M}$ of tested incorporated antioxidants and in their absence (black line) over the whole time range (a) and only during the induction phase (b).

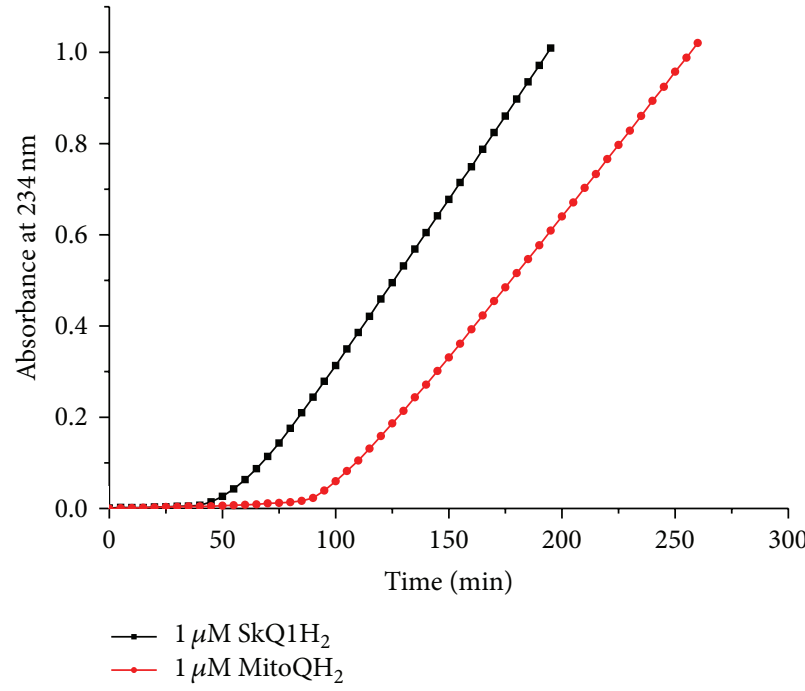

(a)

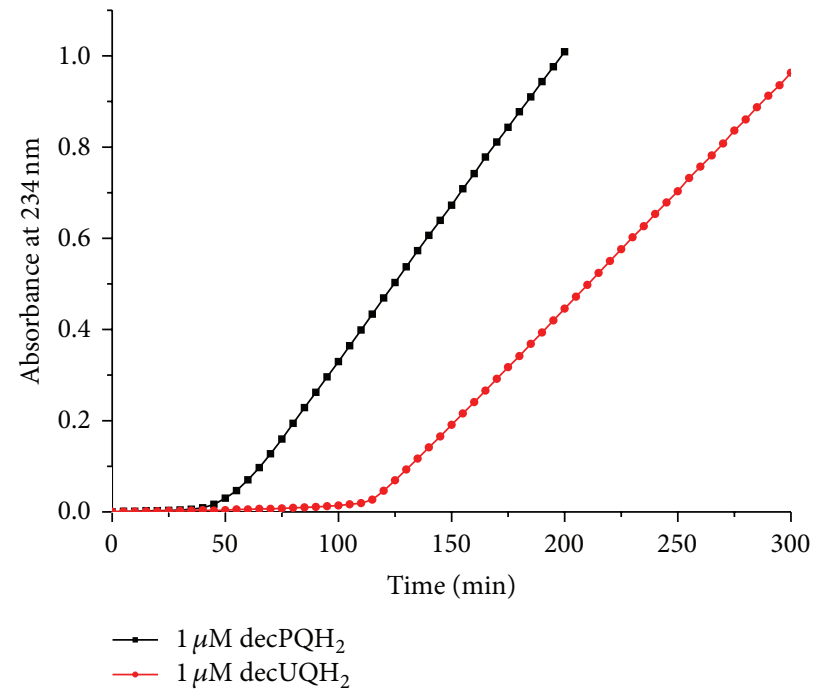

(b)

FIgURE 7: Prevention of the MeO-AMVN-induced oxidation in CL liposomes by incorporated amphiphilic, quinol-based antioxidants. Conditions: pH-buffer A (see Section 2), $100 \mu \mathrm{M} \mathrm{CL}, 50 \mu \mathrm{M} \mathrm{MeO-AMVN}$, and $40^{\circ} \mathrm{C}$. (a, b) Absorbance changes at $234 \mathrm{~nm}$ in the presence of decyl-containing antioxidants (a) and decyltriphenylphosphonium-containing antioxidants (b).

the reason of this retardation, we have studied the impact of $\mathrm{Q}_{10} \mathrm{H}_{2}$ in some more detail (Figure 9(b)). The effect of $\mathrm{Q}_{10} \mathrm{H}_{2}$ was found to be concentration-dependent, as $5 \mu \mathrm{M}$ of $\mathrm{Q}_{10} \mathrm{H}_{2}$ retarded the peroxidation more efficiently than $1 \mu \mathrm{M}$ of $\mathrm{Q}_{10} \mathrm{H}_{2}$. In contrast, the efficiency was independent of the lipid: antioxidant ratio in the added POPG suspension. $1 \mu \mathrm{M}$ of $\mathrm{Q}_{10} \mathrm{H}_{2}$ introduced with $200 \mu \mathrm{M}$ POPG was almost as efficient as $1 \mu \mathrm{M}$ of $\mathrm{Q}_{10} \mathrm{H}_{2}$ added within $40 \mu \mathrm{M}$ POPG (Figure 9(b)). Apparently, only the final concentration of $\mathrm{Q}_{10} \mathrm{H}_{2}$ determined the efficiency, but not the amount of externally added POPG. It is noteworthy that in both experiments (Figures 9(a) and 9(b)) the addition of POPG liposomes without antioxidants (the control sample) did not affect the rate of CL peroxidation. 
TABLE 1: Relative efficiencies of various antioxidants in CL liposomes (note the split $y$-axis). The values for oxidation rates were obtained from the data in Figures 6, 7, and 10 and analogous repetitive experiments as described in Section 2. The chain propagation length for pure CL and each antioxidant was calculated using the radical production rate of $11.8 \mathrm{nM} / \mathrm{min}$, as derived from the $\alpha$-tocopherol run; see Section 4 . The inhibition efficiencies were calculated as ratios of the respective uninhibited and inhibited oxidation rates. The inhibition duration rates were determined from the data in Figures 5-7 and 10.

\begin{tabular}{|c|c|c|c|c|}
\hline Antioxidant & CL oxidation rate, $\mathrm{nM} / \mathrm{min}$ & Chain propagation length & Inhibition efficiency & Inhibition duration (min) \\
\hline Pure CL & $334 \pm 32$ & 28 & - & - \\
\hline $\operatorname{decPQH}_{2}$ & $3.28 \pm 1.1$ & 0.28 & 102 & $48.7 \pm 2.1$ \\
\hline $\mathrm{SkQ1H}_{2}$ & $3.87 \pm 0.6$ & 0.33 & 86 & $58.7 \pm 5.7$ \\
\hline $\operatorname{dec} U Q H_{2}$ & $4.49 \pm 1.2$ & 0.38 & 74 & $114 \pm 4.4$ \\
\hline $\mathrm{MitoQH}_{2}$ & $6.70 \pm 2.0$ & 0.57 & 50 & $91 \pm 8.9$ \\
\hline $\mathrm{Q}_{6} \mathrm{H}_{2}$ & $4.05 \pm 0.5$ & 0.34 & 82 & $124 \pm 9$ \\
\hline $\mathrm{Q}_{10} \mathrm{H}_{2}$ & $4.55 \pm 0.4$ & 0.39 & 73 & $104 \pm 1$ \\
\hline$\alpha$-Tocopherol & $10.6 \pm 0.5$ & 0.90 & 32 & $171 \pm 1$ \\
\hline $\mathrm{HPMC}$ & $8.62 \pm 1.8$ & 0.73 & 39 & N.A. ${ }^{*}$ \\
\hline
\end{tabular}

${ }^{*}$ The duration of action varied dramatically in the case of HPMC because of its variable loss upon the incorporation into liposomes; see Section 4 .

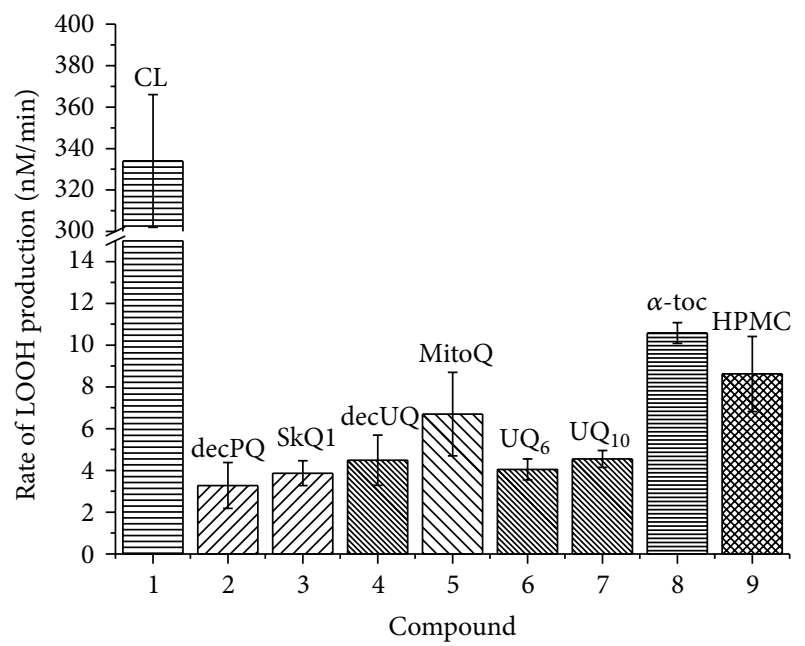

FIGURE 8: The rate of oxidation of liposomal CL in the presence of various antioxidants (data from Figures 5-7 and 10; see also Table 1). $1 \mu \mathrm{M}$ of hydrophobic or amphiphilic antioxidants was added to $100 \mu \mathrm{M}$ of CL liposomes in the presence of $50 \mu \mathrm{M}$ of MeO-AMVN $\left(40^{\circ} \mathrm{C}\right)$. The mean values are represented as bars, and the standard deviations are shown as ticks (see Section 2).

With externally added liposomes we delivered also some further analogues of natural antioxidants, namely, HPMC, $\mathrm{MitoQH}_{2}$, decPQH $\mathrm{H}_{2}$, and decUQH $\mathrm{H}_{2}$, to CL liposomes (Figure $10(\mathrm{a}))$. All these amphiphilic antioxidants were able to diffuse between liposomes via the water phase and prevent the oxidation of CL. Similarly to the CL-incorporated antioxidants (Figures 6 and 7) and the antioxidants introduced as ethanol solutions [19], the ubiquinol-based antioxidants $\left(\mathrm{dec} \mathrm{UQH}_{2}, \mathrm{MitoQH}_{2}\right)$ showed an approximately twice as long inhibitory period compared to plastoquinol-based antioxidants $\left(\mathrm{decPQH}_{2}, \mathrm{SkQ}_{\mathrm{H}}\right)$. Here, HPMC was again barely able to incorporate into the POPG liposomes upon their preparation accounting for the shortest lag period, as compared to other tested antioxidants (Figure 10(a)). Figure 10(b) shows the antioxidant action of compounds that were delivered to the suspension of CL liposomes being dissolved in ethanol, using the approach from our previous study [19]. In this case, HPMC provided a much longer protection with a stoichiometry close to two trapped radicals per one antioxidant molecule.

\section{Discussion}

The present work complements our previous study of quenching the peroxidation of CL liposomes by amphiphilic antioxidants dissolved in ethanol [19]. Here, we tested natural hydrophobic antioxidants such as $\alpha$-tocopherol and ubiquinols, by preincorporating them into the hydrophobic environment of liposomes.

The relative antioxidant efficiency of ubiquinols and tocopherols was earlier assessed in numerous natural and artificial systems and was shown to depend on the nature of the system tested [16, 91-100].

In homogeneous systems, such as hexane [91, 92] or acetonitrile [92], $\alpha$-tocopherol was shown to be more efficient than ubiquinol-10 in protecting fatty acid esters from oxidation.

In heterogeneous systems containing polar/nonpolar interfaces, the affinity of both the antioxidant and substratethe lipid peroxyl radical-to the interfaces could affect the kinetics of radical quenching. In simplest biphasic micellar systems the antioxidant potencies of quinols and $\alpha$ tocopherol were shown to be comparable $[78,92,101]$. In the case of low density lipoprotein (LDL) particles, the carriers of fatty acids in the blood, the literature data on relative antioxidant capacities of ubiquinol and $\alpha$-tocopherol indicate a higher protective effect of ubiquinol $[93,97]$.

Unilamellar liposomes represent a good model for quantitative studying of antioxidants [102]. While liposomes share many traits with physiological systems, their oxidation kinetics can be described by the law of mass action [103, 104]. However, liposomal phospholipid membranes are even more complex than micelles or LDL particles because of the complex nature of their interfaces formed of polar 


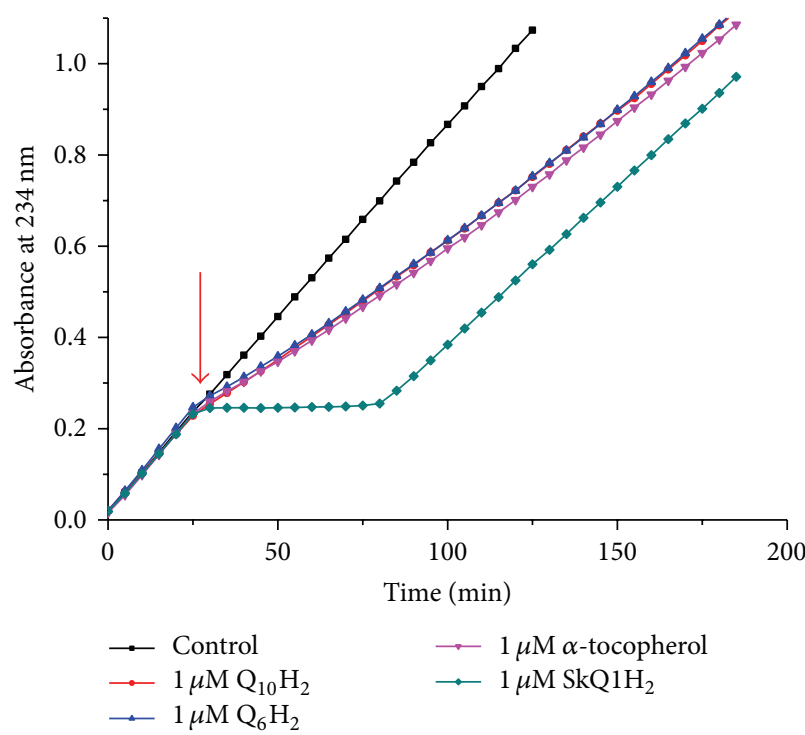

(a)

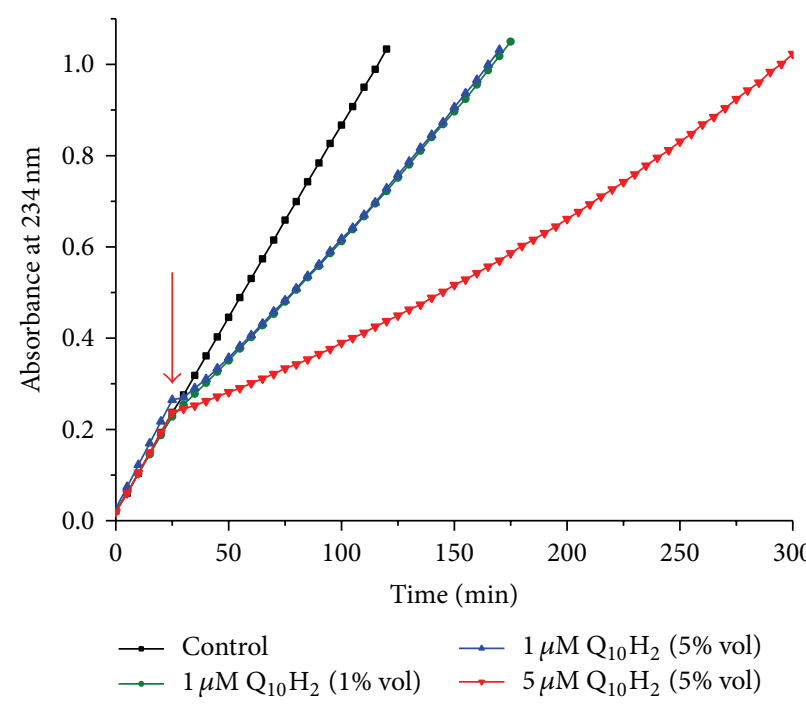

(b)

Figure 9: Prevention of MeO-AMVN-induced oxidation of CL liposomes by antioxidants added externally within POPG liposomes. Peroxidation was started by addition of $50 \mu \mathrm{M} \mathrm{MeO}-\mathrm{AMVN}$ to $100 \mu \mathrm{M}$ CL liposomes at $40^{\circ} \mathrm{C}$ in buffer A. Antioxidant-containing POPG liposomes were added 30 minutes after the start of the experiment, as indicated by arrows. (a) Comparison of $\mathrm{SkQ} \mathrm{H}_{2}$ with natural hydrophobic antioxidants. In each case the final concentrations were $1 \mu \mathrm{M}$ of antioxidants and $40 \mu \mathrm{M}$ of POPG. (b) Radical quenching efficiency of ubiquinol-10 as function of its concentration and the extent of dilution. The amount of added POPG stock suspension was $1 \%(30 \mu \mathrm{L})$ or $5 \%(150 \mu \mathrm{L})$ of the total system volume, which accounts for 40 or $200 \mu \mathrm{M}$ POPG, respectively.

lipid heads that are connected to the hydrophobic tails via glycerol moieties and phosphate groups. The redox active moieties of tocopherols [105] and natural ubiquinols [106108] are expected to dwell on the level of these phosphate groups. Therefore, interactions of antioxidants with these membrane embedded polar groups may additionally affect the antioxidant efficiency and other properties of tocopherols and ubiquinols. Furthermore, the exact position of the polar "phosphate" layer might depend on the nature of the phospholipid; molecular dynamics simulations showed that the phosphate to phosphate distances increased from about $3.8 \mathrm{~nm}$ to about $4.7 \mathrm{~nm}$ when the CL content of a POPC membrane changed from $0 \%$ to $100 \%$ [109]. Therefore, the relative antioxidant efficiency of tocopherols and ubiquinols, as well as their other properties, may depend on the nature of phospholipids and should be determined experimentally for different lipid membranes.

According to the here presented data, all the tested quinols were equally highly effective in protecting CL from peroxidation, as indicated by negligible slopes of absorbance increase at $234 \mathrm{~nm}$ in their presence; see Figures 5-8 and 10, as well as the Table 1. In agreement with previous observations [19], even minute, residual amounts of the antioxidant were sufficient to protect CL from peroxidation. At the same time, $\alpha$-tocopherol and its hydrophilic analogue HPMC were less effective (Figures 6 and 10). These results were rather unexpected, since some of the previous data on concurrent measurements of antioxidant activities of $\alpha$ tocopherol and ubiquinols in lipid bilayers were interpreted as indicating $\alpha$-tocopherol to be either an equally potent [94], or even a better [91] antioxidant than ubiquinol. In these experiments, where both $\alpha$-tocopherol and ubiquinol-10 were present as antioxidants, ubiquinol was consumed before $\alpha$ tocopherol $[91,92,94,97,110,111]$. Building on the previously observed kinetic superiority of $\alpha$-tocopherol over ubiquinol in homogenous model systems $[16,91,92]$ and the observed ability of ubiquinol to recover the $\alpha$-tocopheroxyl radical $[92,112]$, it was generally implied that the faster expenditure of ubiquinol was only apparent, being due to repletion of the promptly oxidized $\alpha$-tocopherol by ubiquinol; see [113, 114] for reviews. Our kinetically resolved data clarify this conundrum, at least, for CL membranes. It follows from our data that all the tested quinol-based antioxidants distinctly outperformed $\alpha$-tocopherol and its hydrophilic analogue HPMC. The faster oxidation of ubiquinol in the presence of $\alpha$-tocopherol in the earlier experiments with liposomes $[91,92,94,97,110,111]$ was, most likely, due to the genuinely faster interaction of ubiquinol with radical species. To what extent our results could be extrapolated to multicomponent mitochondrial membranes, where the potency of different antioxidants is constrained by the rate of their "recycling" by components of the electron transfer chain $[63,110,111]$, is yet to be established.

The radical-scavenging stoichiometry for $\alpha$-tocopherol equals two trapped peroxyl radicals per antioxidant molecule under most of the experimental conditions [10]; the same should be true for its hydrophilic analogue HPMC. Indeed, when HPMC was added as ethanol solution (Figure 10(b)) the duration of its action was almost as long as that of ubiquinol-based antioxidants. The shorter duration of action 


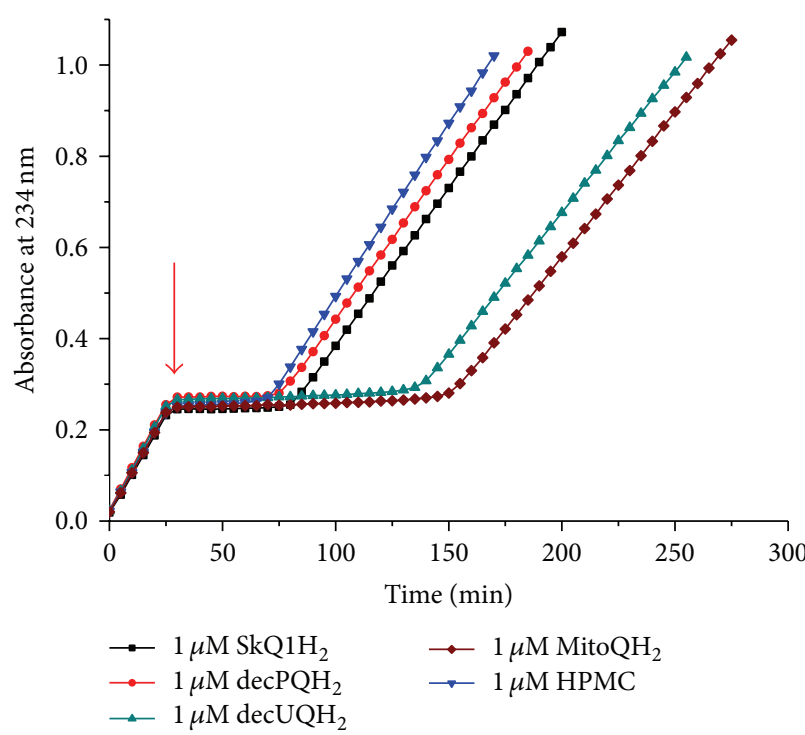

(a)

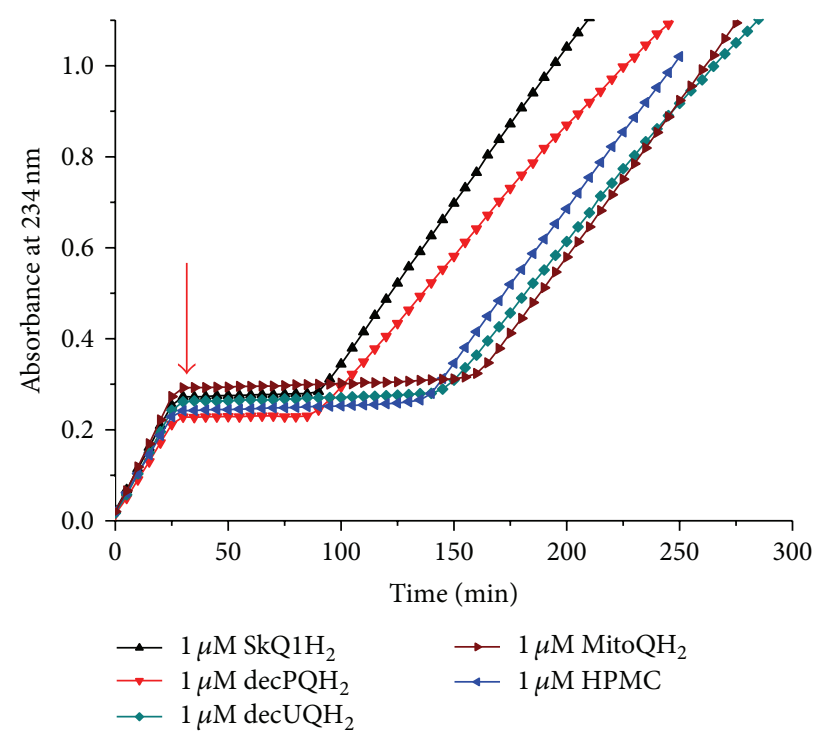

(b)

Figure 10: Prevention of MeO-AMVN-induced oxidation in CL liposomes by various antioxidants added externally within POPG liposomes (a) or as ethanol solutions (b). Peroxidation was started by addition of $50 \mu \mathrm{M} \mathrm{MeO-AMVN}$ to $100 \mu \mathrm{M}$ CL liposomes at $40^{\circ} \mathrm{C}$ in buffer A. The

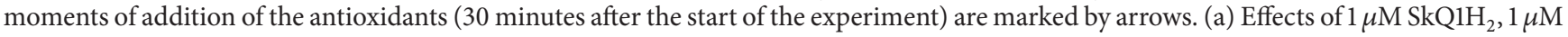

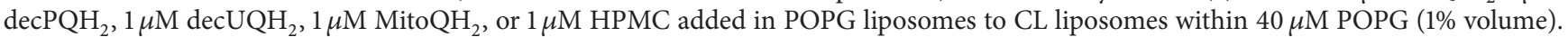

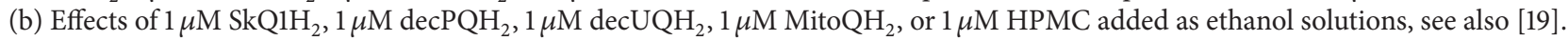

of HPMC upon its addition into liposomes (Figures 6 and 10(a)) might reflect the loss of hydrophilic HPMC upon the sample preparation.

From our data, we could approximately estimate the chain propagation length of CL peroxidation in the membrane, that is, the number of peroxidized fatty acid chains per one radical as generated upon thermal decomposition of $\mathrm{MeO}$ AMVN (see Figure 3). Typically, this value could be obtained from an experiment where the oxidation is inhibited by an antioxidant with known stoichiometry, for example, $\alpha$ tocopherol, for which the number of trapped radicals has been estimated as two [10]. During the lag phase caused by the addition of a potent antioxidant, all the radicals generated are assumed to be eventually quenched, so that the total number of generated radicals should match the concentration of the added antioxidant.

In our experiments, $\alpha$-tocopherol, a reference antioxidant for such calculations, could not block the oxidation of CL completely, unlike quinols.

According to the data in Figure 6, the duration of plateau due to the oxidation of $1 \mu \mathrm{M} \alpha$-tocopherol was about 170 minutes. Assuming that all radicals produced by the $\mathrm{MeO}-$ AMVN decomposition were finally trapped by $\alpha$-tocopherol, and two radicals were taken per one $\alpha$-tocopherol molecule, the rate of radical generation within this system would be $1 \mu \mathrm{M} / 170 \mathrm{~min} \times 2=11.8 \mathrm{nM} / \mathrm{min}$. At the end of plateau the absorbance at $234 \mathrm{~nm}\left(A_{234}\right)$ reached approx. 0.04; this corresponded to $\sim 1.5 \mu \mathrm{M}$ of peroxidized lipid tails (given that the molar extinction of conjugated dienes is about $27400 \mathrm{M}^{-1} \mathrm{~cm}^{-1}$ ); that is, the oxidation rates of $\alpha$-tocopherol and CL coincided under such conditions. Thus, $\alpha$-tocopherol managed to trap directly about half of the radicals that would otherwise attack CL molecules in the absence of the antioxidant.

To calculate the rate of lipid oxidation, $R_{\mathrm{ox}}$, as caused by this radical flux, we calculated the rate of lipid oxidation without inhibitors (the first 25 minutes of the experiment in Figure 10(a)). This value may be derived from the accumulation of conjugated dienes as followed at $234 \mathrm{~nm}$, assuming that the molar extinction coefficient for conjugated dienes is $27400 \mathrm{M}^{-1} \mathrm{~cm}^{-1}$ :

$$
\begin{aligned}
R_{\mathrm{ox}} & =\frac{c(\text { lipid })}{t}=\frac{\left(A_{234}(25 \mathrm{~min})-A_{234}(0 \mathrm{~min})\right)}{(27400 \times 25 \mathrm{~min})} \\
& =3.3 \times 10^{-7} \mathrm{M} \times \mathrm{min}^{-1} .
\end{aligned}
$$

Hence, the rate of uninhibited CL oxidation was $330 \mathrm{nM} / \mathrm{min}$, resulting in a chain propagation length of the CL peroxidation cycle of approximately 28 . In the case of natural ubiquinols as antioxidants the chain propagation length was less than 0.4 (see Table 1), which indicates that the quenching of radicals by the antioxidant (see (5)) was approx. three times faster than the formation of a fatty acid peroxide (see (3a)). Hence, almost all radicals were quenched before getting the opportunity to oxidize a fatty acid, so that quinols essentially prevented the propagation of lipid oxidation. In the presence of $\alpha$-tocopherol, the chain propagation length was about 0.9 , which roughly corresponds to the quenching of only each second radical (see also above).

The duration of the inhibitory effect, as tested here and in the previous study [19], was, in both cases, related to the nature of the antioxidant moiety, decreasing in the series 
$\alpha$-tocopherol $\sim$ ubiquinol $>$ plastoquinol, independently of the rest of the structure of the antioxidant; compare Figures 5-7, 9, and 10, Table 1, and [19]. Hence, although all the quinols got fully oxidized at the end of the lag phase, the duration of the inhibitory action of plastoquinols (this work) and several other quinols [19] was approximately two times shorter than the respective duration for ubiquinols, which, in turn, was almost as long as the duration of the protective effect of $\alpha$-tocopherol. Since $\alpha$-tocopherol is known to quench stoichiometrically two peroxyl radicals per molecule $[10,16$, 92], the number of quenched radicals could be estimated as slightly less than two for ubiquinols and as about one for other tested quinols.

As discussed elsewhere $[10,115,116]$, the decrease in the number of quenched radicals in the case of quinols might be due to the competition of radical species with oxygen for the semiquinones of the antioxidant (see (8)). Most likely, the shorter oxidation time of quinols as compared to $\alpha$ tocopherol was due to the partial oxidation of semiquinones by the oxygen; see the discussion below and $[115,116]$. The slower expenditure of methoxy-substituted ubiquinols, as compared to other quinols, was earlier noted in experiments where oxidation of styrene and methyl linoleate in micelles was induced by a water-soluble azo initiator [78, 87]; the difference was attributed to the slower oxidation of methoxysubstituted semiquinones by oxygen (see (8)) as compared to other semiquinones.

The slower oxidation of methoxy-substituted ubisemiquinones by oxygen (Figures 6, 7, 9, and 10) may have several reasons. Some of the available estimates of the standard redox potential at neutral $\mathrm{pH}\left(E_{o}{ }^{7}\right)$ for the ubiquinone/ubisemiquinone redox pair for protic solvents, such as methanol or water, are higher (up to $90 \mathrm{mV}$ [117]) than the estimates for $E_{o}{ }^{7}$ for the oxygen/superoxide pair under the same conditions (approx. $-150 \mathrm{mV}$ ) [116, 118]. Conversely, the available estimates for $E_{o}{ }^{7}$ of the plastoquinone/plastosemiquinone pair are lower, for example, $-165 \mathrm{mV}$ [115]. With these numbers taken at a face value, the equilibrium of the reaction

$$
\mathrm{O}_{2}+\mathrm{SQ} \longleftrightarrow \mathrm{O}_{2}^{\cdot-}+\mathrm{Q}
$$

should be shifted to the left in case of ubiquinone and to the right in case of plastoquinone, in agreement with our observations and also the earlier reports on the long life of pulse-generated ubiquinone radicals in the presence of oxygen $[117,119]$.

Still, the case might be not so simple. In fact, the potentials of redox pairs that involve radical states strongly depend on the environment and the measurement conditions. Generally, any interaction that would selectively stabilize the polar semiquinone molecule should increase the respective $E_{o}{ }^{7}$ value $[37,115,120]$. Therefore, for semiquinone-involving redox pairs the very term "standard redox potential" $\left(E_{o}\right)$ is meaningful only in relation to particular homogeneous solvents such as water, methanol, or $n$-hexane [115]. For micelles or phospholipid bilayers it is more appropriate to use a "working" term "midpoint redox potential" $\left(E_{m}\right)$ for the efficient redox potential; a term being applicable only to the given system and only under given conditions. No systematic determination of midpoint potentials of quinones in CL bilayers has been done so far. Therefore, the thermodynamics of quinol oxidation in CL membranes awaits its investigators. In addition, the methoxy groups of ubisemiquinones can kinetically hamper the interaction with oxygen, as discussed in more detail in [19]. Particularly, a methoxy group might render the addition of dioxygen molecule to the benzene ring of the semiquinone, which seems to precede the subsequent elimination of superoxide [121].

Hence, as it follows from our data, ubisemiquinone radicals were much less susceptible to oxygen than radicals of other semiquinones when studied within a CL bilayer, which modeled the mitochondrial environment of respiratory complexes. The relative contributions of thermodynamic and kinetic factors in rendering the oxidation of ubisemiquinones by oxygen deserve further clarification. The physiological and evolutionary implications of the poor oxidizability of ubisemiquinones by oxygen are discussed elsewhere [122].

As it follows from Figures $5-8$ and 10 as well as from Table 1, the quinols of the same type (ubiquinols, plastoquinols) but differing in the side chain structure (with decyl, decyltriphenylphosphonium, or prenyl tails) protected CL liposomes from oxidation with similar efficiency. This is also true for $\alpha$-tocopherol and its hydrophilic analogue HPMC (see Figures 6 and 10). This finding correlates with the previous studies where the antioxidants bearing the same active group were equally efficient in protecting liposomes made of two-tail lipids [76, 123].

In experiments with two types of liposomes, namely, oxidizable CL liposomes and antioxidant-containing, nonoxidizable POPG liposomes (Figure 9), all the three tested natural hydrophobic antioxidants $\left(\mathrm{Q}_{6} \mathrm{H}_{2}, \mathrm{Q}_{10} \mathrm{H}_{2}\right.$, and $\alpha$ tocopherol), being much less efficient than $\mathrm{SkQ}_{2} \mathrm{H}_{2}$, slowed down the peroxidation of CL to the same extent (Figure 9(a)). Although we used a hydrophobic azo initiator MeO-AMVN with the oil/water distribution coefficient of about 1000 [124], the prevalence of the aqueous phase in our system over the lipid phase and the more hydrophilic nature of the MeO-AMVN-derived peroxyl radicals as compared to $\mathrm{MeO}-\mathrm{AMVN}$ suggest that lipid peroxidation would be almost exclusively induced from the water phase, which agrees with the fact that the MeO-AMVN radicals can be removed by size exclusion gel filtration [124]. In this case, the extent of radical quenching would not depend on the amount of nonoxidizable lipid. Indeed, a fivefold increase in the amount of nonoxidizable lipid did not affect the rate of CL oxidation (Figure 9(b)).

The rate of CL peroxidation decreased, however, when the total amount of incorporated ubiquinol-10 was increased; see Figure 9(b). It is unlikely that highly hydrophobic antioxidants could escape the POPG membrane and relocate into the CL liposomes to protect them. The exchange of $\alpha$ tocopherol between liposomes was estimated to be in the order of hours $[125,126]$; for more hydrophobic $\mathrm{Q}_{6} \mathrm{H}_{2}$ and $\mathrm{Q}_{10} \mathrm{H}_{2}$ the exchange time should be even longer. In all likelihood, the antioxidants in POPG liposomes "competed" with CL molecules for the water-dissolved MeO-AMVN radicals. In Figure 9, $1 \mu \mathrm{M}$ of hydrophobic antioxidant in 
POPG liposomes slowed down the oxidation of CL liposomes only by a factor of 3 , although the rate constant of radical quenching by an antioxidant (about $3 \times 10^{5} \mathrm{M}^{-1} \mathrm{~s}^{-1}$ ) is 5000 times larger than the rate constant of hydrogen abstraction from polyunsaturated linoleate acid $\left(60 \mathrm{M}^{-1} \mathrm{~s}^{-1}\right.$; see [122] and the references therein). One has to consider, however, that $1 \mu \mathrm{M}$ of antioxidant competed with $100 \mu \mathrm{M}$ of CL. Taking into account four polyunsaturated tails per $1 \mathrm{CL}$ molecule and the chain reaction length of 28 (see above), one gets acceptable correspondence with the experimental data. In the framework of the suggested rational, one would expect that a 5 -fold increase in the amount of antioxidant would decrease the rate of lipid peroxidation also fivefold. We have observed only a threefold drop in the rate (Figure 9(b)); the reason for this minor discrepancy with the expectations should be yet clarified.

While ubiquinols were more efficient than $\alpha$-tocopherol in experiments where antioxidants were added to CL upon preparation of liposomes, the efficiency of natural ubiquinols and $\alpha$-tocopherol was similarly low when they were incorporated in the POPG liposomes (Figure 9(a)). In the latter case, the rate of CL oxidation should slow proportionally to the fraction of the MeO-AMVN radicals that were quenched in the hydrophobic phase of the antioxidant-containing POPG liposomes. Under the assumption that the fraction of $\mathrm{MeO}-$ AMVN radicals that got into the hydrophobic phase of POPG liposomes was independent of the nature of the antioxidant, the data obtained indicate that almost all MeO-AMVN radicals that got into the hydrophobic phase of the POPG liposomes could be quenched, independently of the nature of incorporated hydrophobic antioxidant.

In contrast to hydrophobic antioxidants, the amphiphilic antioxidants, when added with POPG liposomes, fully blocked the oxidation of CL (Figures 9 and 10(a)). Apparently, amphiphilic antioxidants could easily escape the POPG liposomes to interact with the CL liposomes or the MeOAMVN radicals in the solution.

As noted in Introduction, SkQ ions and other amphiphilic antioxidants exhibited pronounced therapeutic effects in vivo [20, 44, 52, 54, 55, 61-74, 127-129], in spite of high levels of hydrophilic and hydrophobic antioxidants present in the cells, even when added in minute amounts. The mechanism of this specific therapeutic action has remained obscure. Here we show that natural ubiquinols extremely efficiently protect CL from oxidation within membrane bilayer, so that their failure in vivo cannot be attributed to poor antioxidant qualities. The reported particular efficiency of amphiphilic antioxidants $[20,44,52,54,55,61-74,127-129]$ might be related to our observation that amphiphilic antioxidants, unlike the hydrophobic ones, can protect CL molecules from the water phase (Figure 9). Indeed, given that many CL molecules are trapped within respiratory enzymes [22], as well as between respiratory enzymes of supercomplexes [26$28]$, that is, close to locations where ROS are generated $[9,33-$ $40,45]$, it is tempting to anticipate that these trapped CL molecules might be the first to become accessible to ROS. This fraction of CL molecules, however, might be secluded both from the bulky ubiquinol-10 molecules with their large isoprenoid tails confined between the membrane leaflets [130] and from the highly polar water-soluble antioxidants, such as glutathion. Earlier we have suggested that these secluded CL molecules could be still accessible to small, nimble, and amphiphilic artificial antioxidants $[19,122]$. The data in Figure 9 indicate that a further advantage of amphiphilic antioxidants over natural ubiquinols and tocopherols is the ability to reach their "occluded" CL targets from the water phase, without the need to get through tightly packed $\alpha$ helices of respiratory supercomplexes. Such a scenario would explain the ability of amphiphilic antioxidants to prevent the CL oxidation in vivo.

Hence, those CL molecules that are occluded within respiratory complexes are close to the sources of ROS and should be the first targets of oxidation in response to a redox imbalance in the respiratory chain. The same secluded CL molecules should be hardly accessible to natural antioxidants. Taken together, these two factors may explain why CL molecules are those preferably oxidized upon oxidative stress $[20,43,44]$. An interaction with cytochrome $c$ molecules at the membrane surface would result in a further oxidation of CL and release of cytochrome $c$ into the cytoplasm [41-44]. Hence, the very susceptibility of CL molecules to oxidation should accelerate the delivery of the message on a redox disaster within mitochondria to the cytoplasmic apoptotic machinery, which might explain the recruiting of CL as the primary sensor of the apoptotic cascade by nature.

In sum, amphiphilic, positively charged antioxidants targeted to mitochondria might specifically protect the occluded CL "sensors" from oxidation and postpone thereby apoptosis. Such postponement might be life-saving in case of acute but transient oxidative stress, such as upon traumas or strokes. Therefore amphiphilic antioxidants, even being added in minute amounts over a huge background of natural ubiquinol and tocopherol, might be efficient in preventing irreversible damage and death.

\section{Conclusions}

We found that natural ubiquinols were as efficient in protecting CL liposomes from peroxidation as ubiquinol-based amphiphilic antioxidants, whereas chromanol-based antioxidants were 2-3 times less efficient. The amphiphilic antioxidants, but not the natural ubiquinols and $\alpha$-tocopherol, could, additionally, interact with the CL bilayer from the water phase. Building on these data, we suggest that the therapeutic efficiency of mitochondrially targeted amphiphilic antioxidants is owing to their ability to protect those CL molecules that are inaccessible to natural hydrophobic antioxidants, being trapped within respiratory supercomplexes. The high susceptibility of such occluded CL molecules may have prompted their recruitment as the sensors of oxidative stress by nature.

\section{Abbreviations}

\author{
CL: $\quad$ Cardiolipin \\ decPQH $\mathrm{PH}_{2}$ : Decylplastoquinol \\ decUQH $\mathrm{U}_{2}$ : Decylubiquinol
}


HPMC: 6-Hydroxy-2,2,5,7,8-pentamethylbenzochroman

MeO-AMVN: 2,2'-Azobis(4-methoxy-2,4-dimethylvaleronitrile)

$\mathrm{MitoQH}_{2}$ : 10-(6'-Ubiquinonyl)decyltriphenylphosphonium

MPT: $\quad$ Mitochondrial permeability transition

LDL: $\quad$ Low density lipoprotein

POPG: 1-Palmitoyl-2-oleoyl-phosphatidylglycerol

$\mathrm{Q}_{6} \mathrm{H}_{2}$ : Ubiquinol-6

$\mathrm{Q}_{10} \mathrm{H}_{2}$ : $\quad$ Ubiquinol-10

ROS: $\quad$ Reactive oxygen species

SkQ: $\quad$ Compounds composed of penetrating cation and quinone

$\mathrm{SkQH}_{2}$ : $\quad$ Reduced (quinol or hydroquinone) forms of SkQ

$\mathrm{SkQ1H}_{2}$ : $\quad$ 10-(6'-Plastoquinonyl)decyltriphenylphosphonium

$\mathrm{SQ}$ or $\mathrm{QH}^{\bullet}$ : Semiquinone.

\section{Competing Interests}

The authors declare that there are no competing interests regarding the publication of this paper.

\section{Acknowledgments}

The authors gratefully acknowledge many useful pieces of advice from Dr. V. A. Roginsky and helpful discussions with Drs. B. V. Chernyak, R. A. Simonyan, and M. Y. Vyssokikh. This work was supported by grants from the Russian Science Foundation (14-14-00592), Institute of Mitoengineering of the Moscow State University, the Deutsche Forschungsgemeinschaft (DFG), the Federal Ministry of Education and Research of Germany, the German Academic Exchange Service (DAAD), and the Open Access Publishing Fund of Osnabrück University.

\section{References}

[1] B. Halliwell and J. M. C. Gutteridge, "Role of free radicals and catalytic metal ions in human disease: an overview," Methods in Enzymology, vol. 186, pp. 1-85, 1990.

[2] V. P. Skulachev, "Membrane-linked systems preventing superoxide formation," Bioscience Reports, vol. 17, no. 3, pp. 347-366, 1997.

[3] G. Lenaz, "The mitochondrial production of reactive oxygen species: mechanisms and implications in human pathology," IUBMB Life, vol. 52, no. 3-5, pp. 159-164, 2001.

[4] E. Niki, "Lipid peroxidation: physiological levels and dual biological effects," Free Radical Biology and Medicine, vol. 47, no. 5, pp. 469-484, 2009.

[5] C.-C. Wu and S. B. Bratton, "Regulation of the intrinsic apoptosis pathway by reactive oxygen species," Antioxidants and Redox Signaling, vol. 19, no. 6, pp. 546-558, 2013.

[6] E. Niki, Y. Yoshida, Y. Saito, and N. Noguchi, "Lipid peroxidation: mechanisms, inhibition, and biological effects," Biochemical and Biophysical Research Communications, vol. 338, no. 1, pp. 668-676, 2005.
[7] M. L. Circu and T. Y. Aw, "Reactive oxygen species, cellular redox systems, and apoptosis," Free Radical Biology and Medicine, vol. 48, no. 6, pp. 749-762, 2010.

[8] P. Pacher, J. S. Beckman, and L. Liaudet, "Nitric oxide and peroxynitrite in health and disease," Physiological Reviews, vol. 87, no. 1, pp. 315-424, 2007.

[9] A. W. Rutherford, A. Osyczka, and F. Rappaport, "Backreactions, short-circuits, leaks and other energy wasteful reactions in biological electron transfer: redox tuning to survive life in $\mathrm{O}_{2}$," FEBS Letters, vol. 586, no. 5, pp. 603-616, 2012.

[10] L. R. C. Barclay and M. R. Vinqvist, "Phenols as antioxidants," in The Chemistry of Phenols, Z. Rappoport, Ed., pp. 839-908, John Wiley \& Sons, New York, NY, USA, 2003.

[11] J. F. Kerr, A. H. Wyllie, and A. R. Currie, "Apoptosis: a basic biological phenomenon with wide-ranging implications in tissue kinetics," British Journal of Cancer, vol. 26, no. 4, pp. 239-257, 1972.

[12] V. P. Skulachev, "Why are mitochondria involved in apoptosis? Permeability transition pores and apoptosis as selective mechanisms to eliminate superoxide-producing mitochondria and cell," FEBS Letters, vol. 397, no. 1, pp. 7-10, 1996.

[13] V. E. Kagan, G. G. Borisenko, Y. Y. Tyurina et al., “Oxidative lipidomics of apoptosis: redox catalytic interactions of cytochrome c with cardiolipin and phosphatidylserine," Free Radical Biology and Medicine, vol. 37, no. 12, pp. 1963-1985, 2004.

[14] C. Wang and R. J. Youle, "The role of mitochondria in apoptosis," Annual Review of Genetics, vol. 43, pp. 95-118, 2009.

[15] A. T. Hoye, J. E. Davoren, P. Wipf, M. P. Fink, and V. E. Kagan, "Targeting mitochondria," Accounts of Chemical Research, vol. 41, no. 1, pp. 87-97, 2008.

[16] L. R. C. Barclay, M. R. Vinqvist, K. Mukai, S. Itoh, and H. Morimoto, "Chain-breaking phenolic antioxidants: steric and electronic effects in polyalkylchromanols, tocopherol analogs, hydroquinones, and superior antioxidants of the polyalkylbenzochromanol and naphthofuran class," Journal of Organic Chemistry, vol. 58, no. 26, pp. 7416-7420, 1993.

[17] E. Niki, "Antioxidants in relation to lipid peroxidation," Chemistry and Physics of Lipids, vol. 44, no. 2-4, pp. 227-253, 1987.

[18] N. Noguchi, H. Yamashita, N. Gotoh, Y. Yamamoto, R. Numano, and E. Niki, "2,2' -azobis (4-methoxy-2,4-dimethylvaleronitrile), a new lipid-soluble azo initiator: application to oxidations of lipids and low-density lipoprotein in solution and in aqueous dispersions," Free Radical Biology and Medicine, vol. 24, no. 2, pp. 259-268, 1998.

[19] A. V. Lokhmatikov, N. E. Voskoboynikova, D. A. Cherepanov et al., "Prevention of peroxidation of cardiolipin liposomes by quinol-based antioxidants," Biochemistry, vol. 79, no. 10, pp. 1081-1100, 2014.

[20] V. P. Skulachev, V. N. Anisimov, Y. N. Antonenko et al., "An attempt to prevent senescence: a mitochondrial approach," Biochimica et Biophysica Acta-Bioenergetics, vol. 1787, no. 5, pp. 437-461, 2009.

[21] Z. T. Schug and E. Gottlieb, "Cardiolipin acts as a mitochondrial signalling platform to launch apoptosis," Biochimica et Biophysica Acta (BBA)-Biomembranes, vol. 1788, no. 10, pp. 2022-2031, 2009.

[22] C. Hunte and S. Richers, "Lipids and membrane protein structures," Current Opinion in Structural Biology, vol. 18, no. 4, pp. 406-411, 2008. 
[23] R. Arias-Cartin, S. Grimaldi, P. Arnoux, B. Guigliarelli, and A. Magalon, "Cardiolipin binding in bacterial respiratory complexes: structural and functional implications," Biochimica et Biophysica Acta, vol. 1817, no. 10, pp. 1937-1949, 2012.

[24] K. Mikel'saar, I. I. Severina, and V. P. Skulachev, "Phospholipids and oxidative phosphorylation," Uspekhi Sovremennoi Biologii, vol. 78, no. 3, pp. 348-370, 1974.

[25] M. Zhang, E. Mileykovskaya, and W. Dowhan, "Gluing the respiratory chain together: cardiolipin is required for supercomplex formation in the inner mitochondrial membrane," Journal of Biological Chemistry, vol. 277, no. 46, pp. 4355343556, 2002.

[26] S. Bazán, E. Mileykovskaya, V. K. P. S. Mallampalli, P. Heacock, G. C. Sparagna, and W. Dowhan, "Cardiolipin-dependent reconstitution of respiratory supercomplexes from purified Saccharomyces cerevisiae complexes III and IV," The Journal of Biological Chemistry, vol. 288, no. 1, pp. 401-411, 2013.

[27] E. Mileykovskaya, P. A. Penczek, J. Fang, V. K. P. S. Mallampalli, G. C. Sparagna, and W. Dowhan, "Arrangement of the respiratory chain complexes in Saccharomyces cerevisiae supercomplex $\mathrm{III}_{2} \mathrm{IV}_{2}$ revealed by single particle cryo-electron microscopy," Journal of Biological Chemistry, vol. 287, no. 27, pp. 23095-23103, 2012.

[28] T. Althoff, D. J. Mills, J.-L. Popot, and W. Kühlbrandt, "Arrangement of electron transport chain components in bovine mitochondrial supercomplex $\mathrm{I}_{1} \mathrm{III}_{2} \mathrm{IV}_{1}$," The EMBO Journal, vol. 30, no. 22, pp. 4652-4664, 2011.

[29] K. B. Busch, G. Deckers-Hebestreit, G. T. Hanke, and A. Y. Mulkidjanian, "Dynamics of bioenergetic microcompartments," The Biological Chemistry, vol. 394, no. 2, pp. 163-188, 2013.

[30] E. Lapuente-Brun, R. Moreno-Loshuertos, R. Aciń-Pérez et al., "Supercomplex assembly determines electron flux in the mitochondrial electron transport chain," Science, vol. 340, no. 6140, pp. 1567-1570, 2013.

[31] A. Boveris and B. Chance, "The mitochondrial generation of hydrogen peroxide. General properties and effect of hyperbaric oxygen," Biochemical Journal, vol. 134, no. 3, pp. 707-716, 1973.

[32] S. S. Korshunov, V. P. Skulachev, and A. A. Starkov, "High protonic potential actuates a mechanism of production of reactive oxygen species in mitochondria," FEBS Letters, vol. 416, no. 1, pp. 15-18, 1997.

[33] J. F. Turrens and A. Boveris, "Generation of superoxide anion by the NADH dehydrogenase of bovine heart mitochondria," Biochemical Journal, vol. 191, no. 2, pp. 421-427, 1980.

[34] L. Kussmaul and J. Hirst, "The mechanism of superoxide production by NADH:ubiquinone oxidoreductase (complex I) from bovine heart mitochondria," Proceedings of the National Academy of Sciences of the United States of America, vol. 103, no. 20, pp. 7607-7612, 2006.

[35] V. G. Grivennikova and A. D. Vinogradov, "Partitioning of superoxide and hydrogen peroxide production by mitochondrial respiratory complex I," Biochimica et Biophysica Acta (BBA)_Bioenergetics, vol. 1827, no. 3, pp. 446-454, 2013.

[36] M. Ksenzenko, A. A. Konstantinov, G. B. Khomutov, A. N. Tikhonov, and E. K. Ruuge, "Effect of electron transfer inhibitors on superoxide generation in the cytochrome $b c_{1}$ site of the mitochondrial respiratory chain," FEBS Letters, vol. 155, no. 1, pp. 19-24, 1983.
[37] A. Y. Mulkidjanian, "Ubiquinol oxidation in the cytochrome $b c_{1}$ complex: reaction mechanism and prevention of shortcircuiting," Biochimica et Biophysica Acta, vol. 1709, no. 1, pp. 5-34, 2005.

[38] D. Malinska, B. Kulawiak, A. P. Kudin et al., "Complex III-dependent superoxide production of brain mitochondria contributes to seizure-related ROS formation," Biochimica et Biophysica Acta, vol. 1797, no. 6-7, pp. 1163-1170, 2010.

[39] M. Sarewicz, M. Dutka, S. Pintscher, and A. Osyczka, “Triplet state of the semiquinone-Rieske cluster as an intermediate of electronic bifurcation catalyzed by cytochrome bc $c_{1}$, Biochemistry, vol. 52, no. 37, pp. 6388-6395, 2013.

[40] L. Bleier and S. Dröse, "Superoxide generation by complex III: from mechanistic rationales to functional consequences," Biochimica et Biophysica Acta, vol. 1827, no. 11-12, pp. 1320-1331, 2013.

[41] V. E. Kagan, V. A. Tyurin, J. Jiang et al., "Cytochrome $c$ acts as a cardiolipin oxygenase required for release of proapoptotic factors," Nature Chemical Biology, vol. 1, no. 4, pp. 223-232, 2005.

[42] V. E. Kagan, P. Wipf, D. Stoyanovsky et al., "Mitochondrial targeting of electron scavenging antioxidants: regulation of selective oxidation vs random chain reactions," Advanced Drug Delivery Reviews, vol. 61, no. 14, pp. 1375-1385, 2009.

[43] V. A. Tyurin, Y. Y. Tyurina, W. Feng et al., "Mass-spectrometric characterization of phospholipids and their primary peroxidation products in rat cortical neurons during staurosporineinduced apoptosis," Journal of Neurochemistry, vol. 107, no. 6, pp. 1614-1633, 2008.

[44] J. Ji, A. E. Kline, A. Amoscato et al., "Lipidomics identifies cardiolipin oxidation as a mitochondrial target for redox therapy of brain injury," Nature Neuroscience, vol. 15, no. 10, pp. 1407-1413, 2012.

[45] A. Musatov and N. C. Robinson, "Susceptibility of mitochondrial electron-transport complexes to oxidative damage. Focus on cytochrome c oxidase," Free Radical Research, vol. 46, no. 11, pp. 1313-1326, 2012.

[46] H. Jin, A. Kanthasamy, A. Ghosh, V. Anantharam, B. Kalyanaraman, and A. G. Kanthasamy, "Mitochondria-targeted antioxidants for treatment of Parkinson's disease: preclinical and clinical outcomes," Biochimica et Biophysica Acta-Molecular Basis of Disease, vol. 1842, no. 8, pp. 1282-1294, 2014.

[47] T. Koyama, M.-Y. Zhu, M. Kinjo, and T. Araiso, "Protective effects of idebenone against alterations in dynamic microstructure induced by lipid peroxidation in rat cardiac mitochondria," Japanese Heart Journal, vol. 32, no. 1, pp. 91-100, 1991.

[48] U. Senin, L. Parnetti, G. Barbagallo-Sangiorgi et al., "Idebenone in senile dementia of Alzheimer type: a multicentre study," Archives of Gerontology and Geriatrics, vol. 15, no. 3, pp. 249260, 1992.

[49] M. Suno and A. Nagaoka, "Inhibition of lipid peroxidation by a novel compound, idebenone (CV-2619)," Japanese Journal of Pharmacology, vol. 35, no. 2, pp. 196-198, 1984.

[50] I. Zs-Nagy, "Chemistry, toxicology, pharmacology and pharmacokinetics of idebenone: a review," Archives of Gerontology and Geriatrics, vol. 11, no. 3, pp. 177-186, 1990.

[51] J. S. Armstrong, M. Whiteman, P. Rose, and D. P. Jones, "The Coenzyme Q10 analog decylubiquinone inhibits the redoxactivated mitochondrial permeability transition: role of mitcohondrial [correction mitochondrial] complex III," The Journal of Biological Chemistry, vol. 278, no. 49, pp. 49079-49084, 2003. 
[52] H. Shao, J. Li, Y. Zhou et al., "Dose-dependent protective effect of propofol against mitochondrial dysfunction in ischaemic/reperfused rat heart: role of cardiolipin," British Journal of Pharmacology, vol. 153, no. 8, pp. 1641-1649, 2008.

[53] K. Zhao, G.-M. Zhao, D. Wu et al., "Cell-permeable peptide antioxidants targeted to inner mitochondrial membrane inhibit mitochondrial swelling, oxidative cell death, and reperfusion injury," The Journal of Biological Chemistry, vol. 279, no. 33, pp. 34682-34690, 2004.

[54] J. Jiang, N. A. Belikova, A. T. Hoye et al., "A mitochondriatargeted nitroxide/hemigramicidin $S$ conjugate protects mouse embryonic cells against gamma irradiation," International Journal of Radiation Oncology Biology Physics, vol. 70, no. 3, pp. 816825, 2008.

[55] M. P. Fink, C. A. Macias, J. Xiao et al., "HemigramicidinTEMPO conjugates: novel mitochondria-targeted anti-oxidants," Biochemical Pharmacology, vol. 74, no. 6, pp. 801-809, 2007.

[56] D. E. Green, "The electromechanochemical model for energy coupling in mitochondria," Biochimica et Biophysica Acta, vol. 346, no. 1, pp. 27-78, 1974.

[57] E. A. Liberman, V. P. Topaly, L. M. Tsofina, A. A. Jasaitis, and V. P. Skulachev, "Mechanism of coupling of oxidative phosphorylation and the membrane potential of mitochondria," Nature, vol. 222, no. 5198, pp. 1076-1078, 1969.

[58] D. O. Levitsky and V. P. Skulachev, "Carnitine: the carrier transporting fatty acyls into mitochondria by means of an electrochemical gradient of $\mathrm{H}^{+}$," Biochimica et Biophysica Acta, vol. 275, no. 1, pp. 33-50, 1972.

[59] M. L. Jauslin, T. Meier, R. A. Smith, and M. P. Murphy, "Mitochondria-targeted antioxidants protect Friedreich Ataxia fibroblasts from endogenous oxidative stress more effectively than untargeted antioxidants," The FASEB Journal, vol. 17, no. 13, pp. 1972-1974, 2003.

[60] G. F. Kelso, C. M. Porteous, C. V. Coulter et al., "Selective targeting of a redox-active ubiquinone to mitochondria within cells: antioxidant and antiapoptotic properties," The Journal of Biological Chemistry, vol. 276, no. 7, pp. 4588-4596, 2001.

[61] L. S. Agapova, B. V. Chernyak, L. V. Domnina et al., "Mitochondria-targeted plastoquinone derivatives as tools to interrupt execution of the aging program. 3. Inhibitory effect of SkQ1 on tumor development from p53-deficient cells," Biochemistry, vol. 73, no. 12, pp. 1300-1316, 2008.

[62] V. N. Anisimov, L. E. Bakeeva, P. A. Egormin et al., "Mitochondria-targeted plastoquinone derivatives as tools to interrupt execution of the aging program. 5. SkQ1 prolongs lifespan and prevents development of traits of senescence," Biochemistry, vol. 73, no. 12, pp. 1329-1342, 2008.

[63] Y. N. Antonenko, A. V. Avetisyan, L. E. Bakeeva et al., "Mitochondria-targeted plastoquinone derivatives as tools to interrupt execution of the aging program. 1. Cationic plastoquinone derivatives: synthesis and in vitro studies," Biochemistry, vol. 73, no. 12, pp. 1273-1287, 2008.

[64] L. E. Bakeeva, I. V. Barskov, M. V. Egorov et al., "Mitochondriatargeted plastoquinone derivatives as tools to interrupt execution of the aging program. 2. Treatment of some ROS- and agerelated diseases (heart arrhythmia, heart infarctions, kidney ischemia, and stroke)," Biochemistry (Moscow), vol. 73, no. 12, pp. 1288-1299, 2008.

[65] V. V. Neroev, M. M. Archipova, L. E. Bakeeva et al., "Mitochondria-targeted plastoquinone derivatives as tools to interrupt execution of the aging program. 4 . Age-related eye disease.
SkQ1 returns vision to blind animals," Biochemistry, vol. 73, no. 12, pp. 1317-1328, 2008.

[66] F. F. Severin, I. I. Severina, Y. N. Antonenko et al., "Penetrating cation/fatty acid anion pair as a mitochondria-targeted protonophore," Proceedings of the National Academy of Sciences of the United States of America, vol. 107, no. 2, pp. 663-668, 2010.

[67] V. P. Skulachev, Y. N. Antonenko, D. A. Cherepanov et al., "Prevention of cardiolipin oxidation and fatty acid cycling as two antioxidant mechanisms of cationic derivatives of plastoquinone (SkQs)," Biochimica et Biophysica Acta (BBA)Bioenergetics, vol. 1797, no. 6-7, pp. 878-889, 2010.

[68] V. N. Anisimov, M. V. Egorov, M. S. Krasilshchikova et al., "Effects of the mitochondria-targeted antioxidant SkQ1 on lifespan of rodents," Aging, vol. 3, no. 11, pp. 1110-1119, 2011.

[69] E. Y. Plotnikov, A. A. Chupyrkina, S. S. Jankauskas et al., "Mechanisms of nephroprotective effect of mitochondria-targeted antioxidants under rhabdomyolysis and ischemia/reperfusion," Biochimica et Biophysica Acta-Molecular Basis of Disease, vol. 1812, no. 1, pp. 77-86, 2011.

[70] E. Y. Plotnikov, M. A. Morosanova, I. B. Pevzner et al., "Protective effect of mitochondria-targeted antioxidants in an acute bacterial infection," Proceedings of the National Academy of Sciences of the United States of America, vol. 110, no. 33, pp. E3100-E3108, 2013.

[71] E. E. Genrikhs, E. V. Stelmashook, O. V. Popova et al., "Mitochondria-targeted antioxidant SkQT1 decreases traumainduced neurological deficit in rat and prevents amyloid- $\beta$ induced impairment of long-term potentiation in rat hippocampal slices," Journal of Drug Targeting, vol. 23, no. 4, pp. 347-352, 2015.

[72] E. N. Iomdina, I. P. Khoroshilova-Maslova, O. V. Robustova et al., "Mitochondria-targeted antioxidant SkQ1 reverses glaucomatous lesions in rabbits," Frontiers in Bioscience, vol. 20, pp. 892-901, 2015.

[73] V. N. Manskikh, O. S. Gancharova, A. I. Nikiforova et al., "Age-associated murine cardiac lesions are attenuated by the mitochondria-targeted antioxidant SkQ1," Histology and Histopathology, vol. 30, no. 3, pp. 353-360, 2015.

[74] I. A. Demyanenko, E. N. Popova, V. V. Zakharova et al., "Mitochondria-targeted antioxidant SkQ1 improves impaired dermal wound healing in old mice," Aging, vol. 7, no. 7, pp. 475485, 2015.

[75] S. Fleischer, H. Klouwen, and G. Brierley, "Studies of the electron transfer system. 38. Lipid composition of purified enzyme preparations derived from beef heart mitochondria," The Journal of Biological Chemistry, vol. 236, pp. 2936-2941, 1961.

[76] L. R. C. Barclay, S. J. Locke, J. M. MacNeil, J. Vankessel, G. W. Burton, and K. U. Ingold, "Autoxidation of micelles and model membranes. Quantitative kinetic measurements can be made by using either water-soluble or lipid-soluble initiators with watersoluble or lipid-soluble chain-breaking antioxidants," Journal of the American Chemical Society, vol. 106, no. 8, pp. 2479-2481, 1984.

[77] M. Cipollone, D. Fiorentini, M. C. Galli, A. M. Sechi, and L. Landi, "Autoxidation and antioxidant activity of ubiquinol homologues in large unilamellar vesicles," Chemistry and Physics of Lipids, vol. 69, no. 1, pp. 87-94, 1994.

[78] V. Roginsky, T. Barsukova, D. Loshadkin, and E. Pliss, "Substituted $p$-hydroquinones as inhibitors of lipid peroxidation," Chemistry and Physics of Lipids, vol. 125, no. 1, pp. 49-58, 2003. 
[79] L. D. Mayer, M. J. Hope, and P. R. Cullis, "Vesicles of variable sizes produced by a rapid extrusion procedure," Biochimica et Biophysica Acta (BBA)-Biomembranes, vol. 858, no. 1, pp. 161168, 1986.

[80] M. J. Hope, M. B. Bally, G. Webb, and P. R. Cullis, "Production of large unilamellar vesicles by a rapid extrusion procedure. Characterization of size distribution, trapped volume and ability to maintain a membrane potential," Biochimica et Biophysica Acta (BBA)_Biomembranes, vol. 812, no. 1, pp. 55-65, 1985.

[81] R. M. C. Dawson, D. C. Elliott, W. H. Elliott, and K. M. Jones, Data for Biochemical Research, Clarendon Press, Oxford, UK, 2nd edition, 1969.

[82] R. M. C. Dawson, D. C. Elliott, W. H. Elliott, and K. M. Jones, Data for Biochemical Research, Clarendon Press, Oxford, UK, 3rd edition, 1986.

[83] P. R. Rich, "Electron and proton transfers through quinones and cytochrome bc complexes," Biochimica et Biophysica Acta, vol. 768, no. 1, pp. 53-79, 1984.

[84] W. Liu, N. A. Porter, C. Schneider, A. R. Brash, and H. Yin, "Formation of 4-hydroxynonenal from cardiolipin oxidation: intramolecular peroxyl radical addition and decomposition," Free Radical Biology and Medicine, vol. 50, no. 1, pp. 166-178, 2011.

[85] H. Yin and M. Zhu, "Free radical oxidation of cardiolipin: chemical mechanisms, detection and implication in apoptosis, mitochondrial dysfunction and human diseases," Free Radical Research, vol. 46, no. 8, pp. 959-974, 2012.

[86] E. Niki, "Assessment of antioxidant capacity in vitro and in vivo," Free Radical Biology and Medicine, vol. 49, no. 4, pp. 503-515, 2010.

[87] D. Loshadkin, V. Roginsky, and E. Pliss, "Substituted phydroquinones as a chain-breaking antioxidant during the oxidation of styrene," International Journal of Chemical Kinetics, vol. 34, no. 3, pp. 162-171, 2002.

[88] T. Doba, G. W. Burton, K. U. Ingold, and M. Matsuo, " $\alpha$ Tocopheroxyl decay-lack of effect of oxygen," Journal of the Chemical Society, Chemical Communications, no. 7, pp. 461-462, 1984.

[89] R. C. R. M. Vossen, M. C. E. van Dam-Mieras, G. Hornstra, and R. F. A. Zwaal, "Continuous monitoring of lipid peroxidation by measuring conjugated diene formation in an aqueous liposome suspension," Lipids, vol. 28, no. 9, pp. 857-861, 1993.

[90] H. Esterbauer, G. Striegl, H. Puhl, and M. Rotheneder, "Continuous monitoring of in vztro oxidation of human low density lipoprotein," Free Radical Research Communications, vol. 6, no. 1, pp. 67-75, 1989.

[91] Y. Yamamoto, E. Komuro, and E. Niki, "Antioxidant activity of ubiquinol in solution and phosphatidylcholine liposome," Journal of Nutritional Science and Vitaminology, vol. 36, no. 5, pp. 505-511, 1990.

[92] H. Shi, N. Noguchi, and E. Niki, "Comparative study on dynamics of antioxidative action of $\alpha$-tocopheryl hydroquinone, ubiquinol, and $\alpha$-tocopherol against lipid peroxidation," Free Radical Biology and Medicine, vol. 27, no. 3-4, pp. 334-346, 1999.

[93] K. U. Ingold, V. W. Bowry, R. Stocker, and C. Walling, "Autoxidation of lipids and antioxidation by $\alpha$-tocopherol and ubiquinol in homogeneous solution and in aqueous dispersions of lipids: unrecognized consequences of lipid particle size as exemplified by oxidation of human low density lipoprotein," Proceedings of the National Academy of Sciences of the United States of America, vol. 90, no. 1, pp. 45-49, 1993.
[94] B. Frei, M. C. Kim, and B. N. Ames, "Ubiquinol-10 is an effective lipid-soluble antioxidant at physiological concentrations," Proceedings of the National Academy of Sciences of the United States of America, vol. 87, no. 12, pp. 4879-4883, 1990.

[95] J. Kruk, M. Jemioła-Rzemińska, and K. Strzałka, "Plastoquinol and $\alpha$-tocopherol quinol are more active than ubiquinol and $\alpha$ tocopherol in inhibition of lipid peroxidation," Chemistry and Physics of Lipids, vol. 87, no. 1, pp. 73-80, 1997.

[96] D. Fiorentini, L. Cabrini, and L. Landi, "Ubiquinol-3 and ubiquinol-7 exhibit similar antioxidant activity in model membranes," Free Radical Research, vol. 18, no. 4, pp. 201-209, 1993.

[97] R. Stocker, V. W. Bowry, and B. Frei, "Ubiquinol-10 protects human low density lipoprotein more efficiently against lipid peroxidation than does $\alpha$-tocopherol," Proceedings of the National Academy of Sciences of the United States of America, vol. 88, no. 5, pp. 1646-1650, 1991.

[98] V. W. Bowry and R. Stocker, "Tocopherol-mediated peroxidation. The prooxidant effect of vitamin $\mathrm{E}$ on the radical-initiated oxidation of human low-density lipoprotein," Journal of the American Chemical Society, vol. 115, no. 14, pp. 6029-6044, 1993.

[99] V. W. Bowry, D. Mohr, J. Cleary, and R. Stocker, "Prevention of tocopherol-mediated peroxidation in ubiquinol-10-free human low density lipoprotein," Journal of Biological Chemistry, vol. 270, no. 11, pp. 5756-5763, 1995.

[100] S. R. Thomas, J. Neužil, and R. Stocker, "Cosupplementation with coenzyme Q prevents the prooxidant effect of alphatocopherol and increases the resistance of LDL to transition metal-dependent oxidation initiation," Arteriosclerosis, Thrombosis, and Vascular Biology, vol. 16, no. 5, pp. 687-696, 1996.

[101] W. A. Pryor, T. Strickland, and D. F. Church, "Comparison of the efficiencies of several natural and synthetic antioxidants in aqueous sodium dodecyl sulfate micelle solutions," Journal of the American Chemical Society, vol. 110, no. 7, pp. 2224-2229, 1988.

[102] D. Fiorentini, M. Cipollone, M. C. Galli, A. Pugnaloni, G. Biagini, and L. Landi, "Characterization of large unilamellar vesicles as models for studies of lipid peroxidation initiated by azocompounds," Free Radical Research, vol. 21, no. 5, pp. 329339, 1994.

[103] L. R. C. Barclay and K. U. Ingold, "Autoxidation of biological molecules. 2. The autoxidation of a model membrane-a comparison of the autoxidation of egg lecithin phosphatidylcholine in water and in chlorobenzene," Journal of the American Chemical Society, vol. 103, no. 21, pp. 6478-6485, 1981.

[104] L. R. C. Barclay and K. U. Ingold, "Autoxidation of a model membrane. A comparison of the autoxidation of egg lecithin phosphatidylcholine in water and in chlorobenzene," Journal of the American Chemical Society, vol. 102, no. 26, pp. 7792-7794, 1980.

[105] J. Atkinson, T. Harroun, S. R. Wassall, W. Stillwell, and J. Katsaras, "The location and behavior of $\alpha$-tocopherol in membranes," Molecular Nutrition and Food Research, vol. 54, no. 5, pp. 641-651, 2010.

[106] J. A. Nilsson, A. Lyubartsev, L. A. Eriksson, and A. Laaksonen, "Molecular dynamics simulations of ubiquinone; a survey over torsional potentials and hydrogen bonds," Molecular Physics, vol. 99, no. 21, pp. 1795-1804, 2001.

[107] R. Fiorini, L. Ragni, S. Ambrosi, G. P. Littarru, E. Gratton, and T. Hazlett, "Fluorescence studies of the interactions of ubiquinol10 with liposomes," Photochemistry and Photobiology, vol. 84, no. 1, pp. 209-214, 2008. 
[108] A. Ausili, A. Torrecillas, F. Aranda et al., "Redox state of coenzyme Q10 determines its membrane localization," Journal of Physical Chemistry B, vol. 112, no. 40, pp. 12696-12702, 2008.

[109] M. Dahlberg and A. Maliniak, "Molecular dynamics simulations of cardiolipin bilayers," Journal of Physical Chemistry B, vol. 112, no. 37, pp. 11655-11663, 2008.

[110] A. Lass and R. S. Sohal, "Electron transport-linked ubiquinonedependent recycling of $\alpha$-tocopherol inhibits autooxidation of mitochondrial membranes," Archives of Biochemistry and Biophysics, vol. 352, no. 2, pp. 229-236, 1998.

[111] V. Kagan, E. Serbinova, and L. Packer, "Antioxidant effects of ubiquinones in microsomes and mitochondria are mediated by tocopherol recycling," Biochemical and Biophysical Research Communications, vol. 169, no. 3, pp. 851-857, 1990.

[112] D. A. Stoyanovsky, A. N. Osipov, P. J. Quinn, and V. E. Kagan, "Ubiquinone-dependent recycling of vitamin $\mathrm{E}$ radicals by superoxide," Archives of Biochemistry and Biophysics, vol. 323, no. 2, pp. 343-351, 1995.

[113] P. J. Quinn, J. P. Fabisiak, and V. E. Kagan, "Expansion of antioxidant function of vitamin E by coenzyme Q, BioFactors, vol. 9, no. 2-4, pp. 149-154, 1999.

[114] V. E. Kagan, J. P. Fabisiak, and P. J. Quinn, "Coenzyme Q and vitamin E need each other as antioxidants," Protoplasma, vol. 214, no. 1-2, pp. 11-18, 2000.

[115] Y. Song and G. R. Buettner, "Thermodynamic and kinetic considerations for the reaction of semiquinone radicals to form superoxide and hydrogen peroxide," Free Radical Biology and Medicine, vol. 49, no. 6, pp. 919-962, 2010.

[116] V. Roginsky and T. Barsukova, "Kinetics of oxidation of hydroquinones by molecular oxygen. Effect of superoxide dismutase," Journal of the Chemical Society, Perkin Transactions 2, no. 7, pp. 1575-1582, 2000.

[117] K. B. Patel and R. L. Willson, "Semiquinone free radicals and oxygen. Pulse radiolysis study of one electron transfer equilibria," Journal of the Chemical Society, Faraday Transactions 1: Physical Chemistry in Condensed Phases, vol. 69, no. 4, pp. 814$825,1973$.

[118] A. Maroz, R. F. Anderson, R. A. J. Smith, and M. P. Murphy, "Reactivity of ubiquinone and ubiquinol with superoxide and the hydroperoxyl radical: implications for in vivo antioxidant activity," Free Radical Biology and Medicine, vol. 46, no. 1, pp. 105-109, 2009.

[119] R. Pethig, P. R. C. Gascoyne, J. A. McLaughlin, and A. SzentGyorgyi, "Ascorbate-quinone interactions: electrochemical, free radical, and cytotoxic properties," Proceedings of the National Academy of Sciences of the United States of America, vol. 80, no. 1 I, pp. 129-132, 1983.

[120] W. A. Cramer and D. B. Knaff, Energy Transduction in Biological Membranes: A Textbook of Bioenergetics, Springer, 1990.

[121] L. Valgimigli, R. Amorati, M. G. Fumo et al., "The unusual reaction of semiquinone radicals with molecular oxygen," Journal of Organic Chemistry, vol. 73, no. 5, pp. 1830-1841, 2008.

[122] D. V. Dibrova, D. A. Cherepanov, M. Y. Galperin, V. P. Skulachev, and A. Y. Mulkidjanian, "Evolution of cytochrome $b c$ complexes: from membrane-anchored dehydrogenases of ancient bacteria to triggers of apoptosis in vertebrates," Biochimica et Biophysica Acta-Bioenergetics, vol. 1827, no. 11-12, pp. 14071427, 2013.

[123] E. Niki, A. Kawakami, M. Saito, Y. Yamamoto, J. Tsuchiya, and Y. Kamiya, "Effect of phytyl side chain of vitamin E on its antioxidant activity," The Journal of Biological Chemistry, vol. 260, no. 4, pp. 2191-2196, 1985.
[124] S. M. Culbertson, M. R. Vinqvist, L. R. C. Barclay, and N. A. Porter, "Minimizing tocopherol-mediated radical phase transfer in low-density lipoprotein oxidation with an amphiphilic unsymmetrical azo initiator," Journal of the American Chemical Society, vol. 123, no. 37, pp. 8951-8960, 2001.

[125] L. R. C. Barclay, K. A. Mclaughlin, and M. R. Vinquist, "The transfer of antioxidants between liposomes," Journal of Liposome Research, vol. 5, no. 4, pp. 955-979, 1995.

[126] L. R. C. Barclay, F. Antunes, Y. Egawa et al., "The efficiency of antioxidants delivered by liposomal transfer," Biochimica et Biophysica Acta, vol. 1328, no. 1, pp. 1-12, 1997.

[127] J. Jiang, D. A. Stoyanovsky, N. A. Belikova et al., "A mitochondria-targeted triphenylphosphonium-conjugated nitroxide functions as a radioprotector/mitigator," Radiation Research, vol. 172, no. 6, pp. 706-717, 2009.

[128] J. Jiang, I. Kurnikov, N. A. Belikova et al., "Structural requirements for optimized delivery, inhibition of oxidative stress, and antiapoptotic activity of targeted nitroxides," Journal of Pharmacology and Experimental Therapeutics, vol. 320, no. 3, pp. 1050-1060, 2007.

[129] Z. Huang, J. Jiang, N. A. Belikova, D. A. Stoyanovsky, V. E. Kagan, and A. H. Mintz, "Protection of normal brain cells from $\gamma$-irradiation-induced apoptosis by a mitochondriatargeted triphenyl-phosphonium-nitroxide: a possible utility in glioblastoma therapy," Journal of Neuro-Oncology, vol. 100, no. 1, pp. 1-8, 2010.

[130] T. Hauß, S. Dante, T. H. Haines, and N. A. Dencher, "Localization of coenzyme Q10 in the center of a deuterated lipid membrane by neutron diffraction," Biochimica et Biophysica Acta (BBA)-Bioenergetics, vol. 1710, no. 1, pp. 57-62, 2005. 


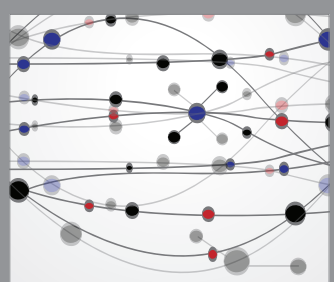

The Scientific World Journal
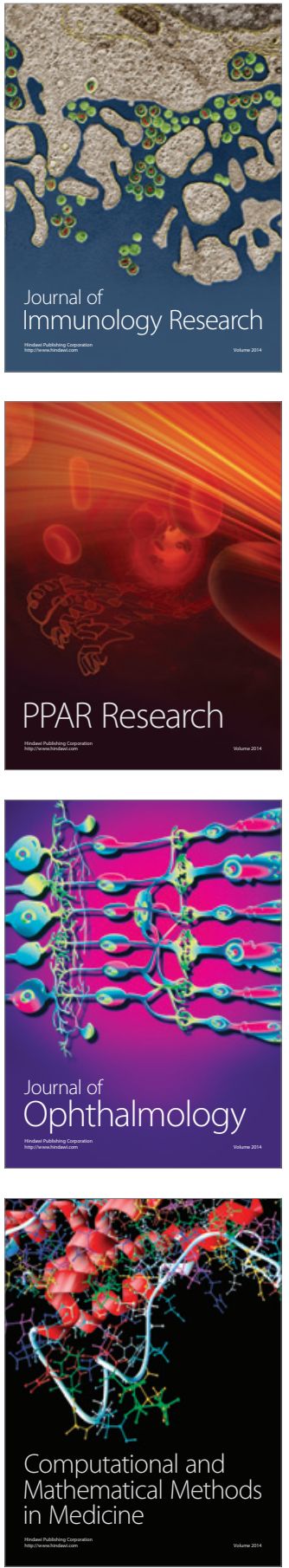

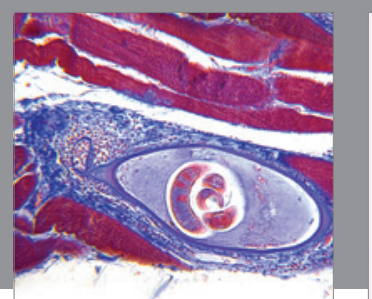

Gastroenterology Research and Practice

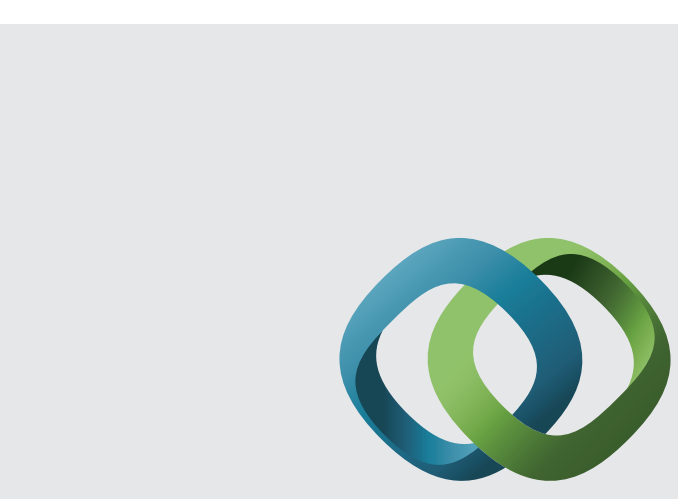

\section{Hindawi}

Submit your manuscripts at

http://www.hindawi.com
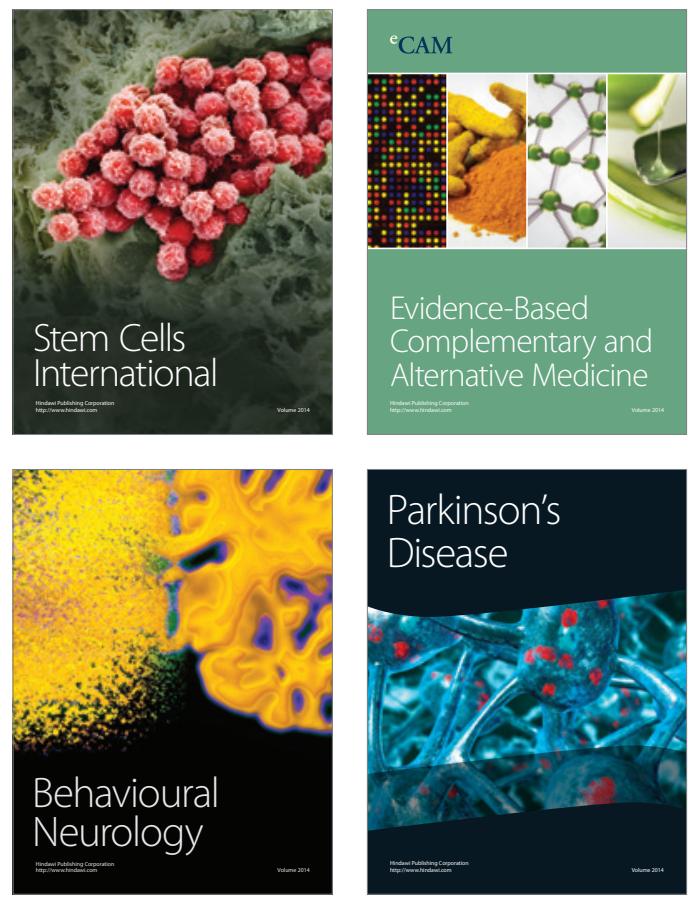
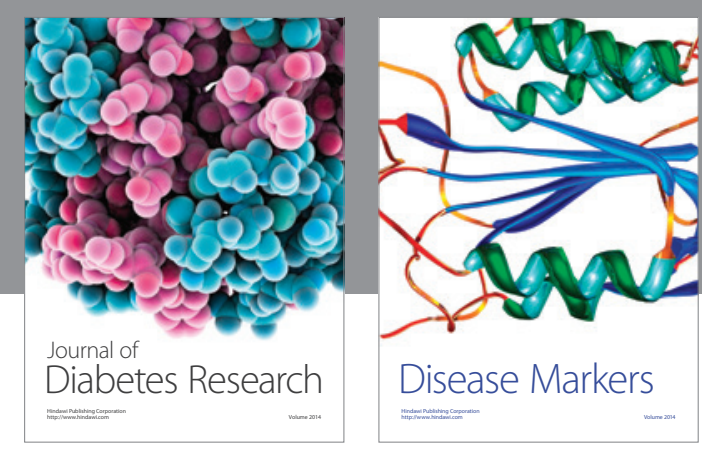

Disease Markers
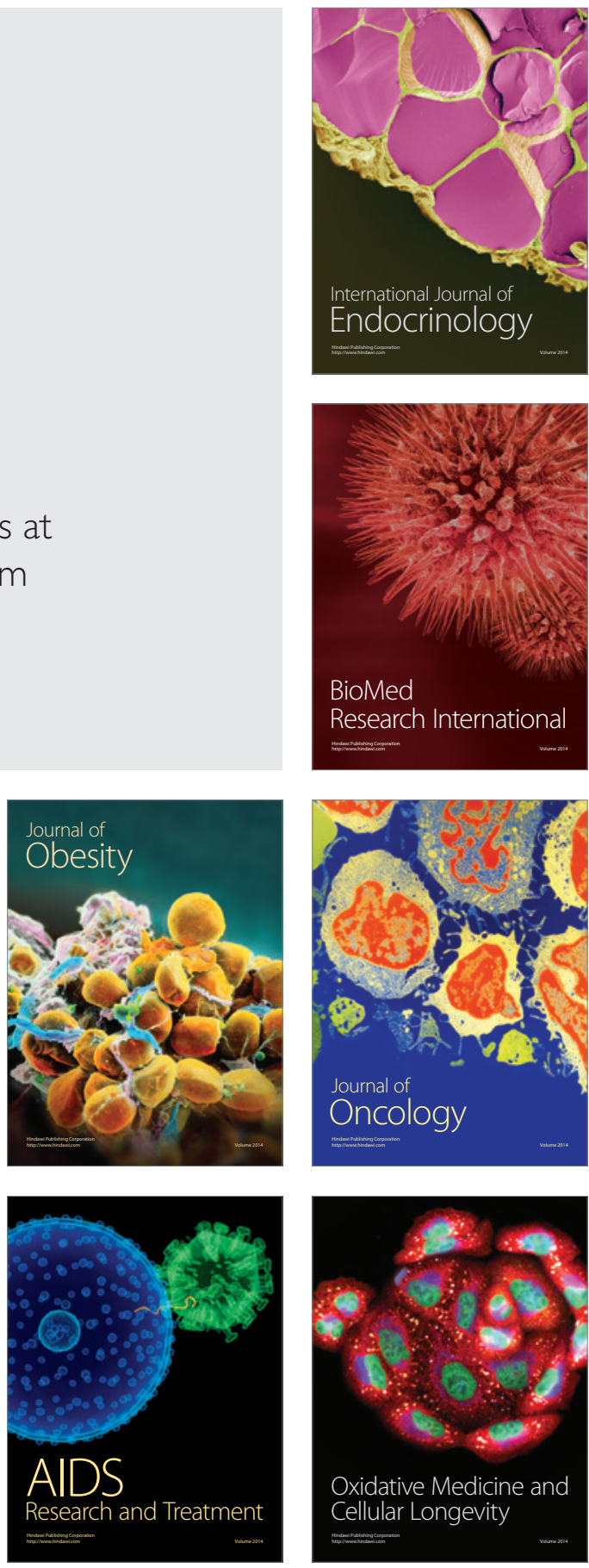